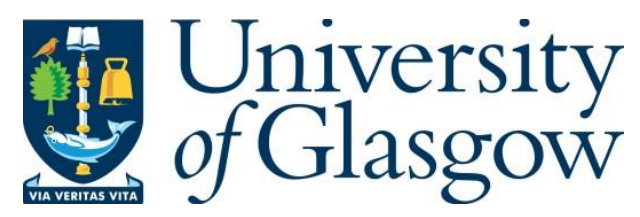

Liang, Y., Manninen, T., Zhao, O., Walport, F. and Gardner, L. (2019) Elevated temperature material properties of a new high-chromium austenitic stainless steel. Journal of Constructional Steel Research, 152, pp. 261-273.

There may be differences between this version and the published version. You are advised to consult the publisher's version if you wish to cite from it.

http://eprints.gla.ac.uk/186400/

Deposited on: 10 May 2019

Enlighten - Research publications by members of the University of Glasgow http://eprints.gla.ac.uk 
Liang, Y., Manninen, T., Zhao, O., Walport, F. and Gardner, L. (2018). Elevated temperature material properties of a new high-chromium austenitic stainless steel. Journal of Constructional Steel Research. In press.

\title{
Elevated temperature material properties of a new high-chromium
}

\section{austenitic stainless steel}

\author{
Yating Liang a, Timo Manninen ${ }^{\mathrm{b}}$, Ou Zhao ${ }^{\mathrm{c}, *}$, Fiona Walport ${ }^{\mathrm{d}}$, Leroy Gardner ${ }^{\mathrm{e}}$ \\ ${ }^{a, c}$ School of Civil and Environmental Engineering, Nanyang Technological University, 50 Nanyang \\ Avenue, 639798 Singapore, Singapore \\ ${ }^{\mathrm{b}}$ Outokumpu Tornio R\&D Centre, Finland \\ ${ }^{\mathrm{d}, \mathrm{e}}$ Department of Civil and Environmental Engineering, Imperial College London, London, UK \\ * Corresponding author, Phone: +65 67906934 \\ Email: ou.zhao@ntu.edu.sg
}

\begin{abstract}
:
A testing programme was conducted to investigate the material properties of a new highchromium grade of austenitic stainless steel - EN 1.4420 at elevated temperatures. A total of 164 tensile coupons extracted from both cold-rolled and hot-rolled sheets were tested; 80 coupons were tested isothermally with temperatures ranging from $25{ }^{\circ} \mathrm{C}$ to $1100{ }^{\circ} \mathrm{C}$, and 84 were tested anisothermally with stress levels ranging from $10 \%$ to $90 \%$ of the material $0.2 \%$ proof stress at room temperature. The experimentally derived reduction factors for the key material properties were compared with existing design values. Design recommendations for the elevated temperature reduction factors were then proposed for this new grade, and a twostage Ramberg-Osgood model was shown to be able to accurately represent the material stressstrain response at elevated temperature.
\end{abstract}

\section{Keywords:}

Elevated temperatures, High-chromium austenitic stainless steel, Material properties, Steady state tests, Reduction factors; Transient state tests 


\section{Introduction}

Recent decades have witnessed an increasing use of stainless steel in a variety of engineering applications, owing to its aesthetic appeal, favourable mechanical properties, excellent ductility and superior resistance against corrosion and fire in comparison to carbon steel. The high initial material cost, coupled with the fledgling nature of the design codes that are overly conservative in parts, represent barriers to the wider utilisation of stainless steel in construction engineering. In order to overcome these drawbacks, in-depth studies into the mechanical behaviour of stainless steel materials and members [1-9] have been conducted, and more accurate and efficient design rules have been developed. In parallel with this, novel stainless steel grades that maintain the key favourable material properties, but at a lower cost, continue to be developed, a recent example being a new high-chromium austenitic stainless steel - grade 1.4420. Compared to the commonly used Cr-Ni-Mo austenitic stainless steel grades such as 1.4404 and 1.4432 , this new grade has lower nickel and molybdenum contents, thus leading to a lower and more stable material price, and possesses higher contents of chromium and nitrogen, resulting in higher strength [10] and better corrosion resistance [11]. The nominal mechanical properties of grade 1.4420 stainless steel are given in Table 1 , where $f_{0.2 p}$ is the $0.2 \%$ proof stress, $f_{1.0 p}$ is the $1.0 \%$ proof stress and $f_{u}$ is the ultimate tensile stress. The pitting resistance equivalent number (PREN), which is a predictive measure of the corrosion resistance of stainless steels, is equal to 26 for grade 1.4420 stainless steel; other typical high corrosionresistant stainless steel grades such as 1.4435 and LDX 2101 have the same PREN values. As part of a comprehensive experimental study that is currently being carried out to investigate the mechanical performance of this new stainless steel grade, this paper focuses on the elevated temperature material properties. Previous relevant experimental studies on the material properties of stainless steel alloys at elevated temperatures are briefly reviewed herein. Kouhi 
et al. [12] performed material tensile coupon tests on stainless steel grades 1.4571 and 1.4301 at elevated temperatures and concluded that austenitic stainless steels are generally suitable to be used in structures without fire protection. Gardner and Baddoo [13] conducted elevated temperature material tests on austenitic $(1.4301,1.4401$ and 1.4571), duplex (1.4462) and ferritic (1.4003) stainless steels, and compared the derived strength and stiffness reduction factors with those of carbon steel. Chen and Young [14] carried out material tests on austenitic (1.4301) and duplex (1.4462) stainless steel grades at elevated temperatures, and proposed unified equations, based on a lower bound to the experimental results, to predict the material properties at elevated temperatures for the two considered stainless steel grades. Huang and Young [15] investigated the high temperature material properties of lean duplex stainless steel (1.4162), and proposed strength and stiffness reduction factors, based on the unified equations. Manninen and Säynäjäkangas [16] carried out elevated temperature material tests on a variety of ferritic stainless steel grades $(1.4003,1.4016,1.4509,1.4521$ and 1.4621) and proposed strength reduction factors, on the basis of the mean values of the test data. Gardner et al. [17] conducted material tests on austenitic (1.4307 and 1.4311) and duplex (1.4162 and 1.4362) stainless steel reinforcing bars at elevated temperatures, and concluded that the strength reduction factors derived for stainless steel plates and strips can also be applied to stainless steel reinforcement.

The present paper aims to investigate the material properties of the new austenitic stainless steel grade 1.4420 at elevated temperatures and to assess the applicability of the existing strength and stiffness reduction factors to this material. The paper begins with a description of the elevated temperature material testing programme, which included 80 steady state tests and 84 transient state tests. The test results were then transformed into the form of reduction factors for material properties, which were analysed and compared against the design values tabulated 
in the European code EN 1993-1-2 [18] and proposed by Gardner et al. [19]. Design recommendations for the elevated temperature reduction factors were then made for the new studied grade 1.4420 austenitic stainless steel. Finally, a two-stage Ramberg-Osgood model [19] was applied to represent the material stress-strain responses at elevated temperatures.

\section{Experimental programme}

\subsection{General}

An experimental programme was firstly conducted to investigate the material properties of grade 1.4420 austenitic stainless steel at elevated temperatures, using both steady and transient state testing methods. Compared to other commonly used Cr-Ni-Mo austenitic stainless steel grades such as 1.4404 and 1.4432 , this new grade possesses lower nickel and molybdenum contents but higher contents of chromium and nitrogen; the chemical composition of the tested material is shown in Table 2. A total of 164 tensile coupons extracted from both cold-rolled and hot-rolled sheet materials of grade 1.4420 stainless steel were tested; 80 steady state tests and 84 transient state tests were performed, as summarised in Table 3 . The dimensions of the tensile coupons conformed to the requirements of ISO EN 10002-5 [20], with the width and length of the parallel part of the coupons equal to $10 \mathrm{~mm}$ and $75 \mathrm{~mm}$, respectively.

The material tensile coupon tests were performed using a Zwick Z250/SW5A testing machine, as shown in Fig. 1. For the isothermal tests, an environmental chamber, as depicted in Fig. 2, was used for temperatures up to $550{ }^{\circ} \mathrm{C}$, while for the isothermal tests at temperatures above $550{ }^{\circ} \mathrm{C}$ and for the anisothermal tests, a high temperature furnace, as shown in Fig. 3, was employed. The furnace comprised three zones, with the air temperature in each zone monitored 
and controlled by a thermocouple connected to the Eurotherm 2416 Temperature Controller. Three K-type thermocouples were attached to each tensile coupon to measure its surface temperature. A side-entry extensometer of $50 \mathrm{~mm}$ initial gauge length with ceramic sensor arms was mounted to the specimens to measure their elongations.

\subsection{Steady state tests}

In the steady state (isothermal) tests, the coupons were heated to a specified temperature, and then loaded until fracture. Steady state tests were carried out on coupons extracted from $1 \mathrm{~mm}$ thick cold-rolled sheets and $6 \mathrm{~mm}$ thick hot-rolled sheets, at temperatures ranging from room temperature to $1100{ }^{\circ} \mathrm{C}$ at intervals of $100{ }^{\circ} \mathrm{C}$ between room temperature and $500{ }^{\circ} \mathrm{C}$ and at intervals of $50{ }^{\circ} \mathrm{C}$ between $500{ }^{\circ} \mathrm{C}$ and $1100{ }^{\circ} \mathrm{C}$. At each specified temperature, two repeated tests were conducted, except when there was a large disparity between the two sets of experimental results, in which case a third test was carried out. During testing, the coupons were firstly heated to a target temperature, which was then maintained for $10 \mathrm{~min}$; note that the coupons were only gripped at one end during the heating phase, so that free thermal expansion was allowed and no longitudinal stress was induced into the coupons. Then, the specimens were loaded in tension under displacement control at a constant testing rate of $0.4 \mathrm{~mm} / \mathrm{min}$ up to a strain value of $2.5 \%$ for the hot-rolled coupons and $3.5 \%$ for the cold-rolled coupons, after which a higher loading rate of $15 \mathrm{~mm} / \mathrm{min}$ was adopted until fracture of the coupon. The resulting strain rates were $0.0027 \mathrm{~min}^{-1}$ and $0.1 \mathrm{~min}^{-1}$ up to and beyond the $2.5 \%$ (or $3.5 \%$ ) strain, respectively, which conformed to requirements given in EN ISO 10002-5 [20]. 


\subsection{Transient state tests}

In the transient state (anisothermal) tests, the coupons were firstly loaded in tension to a target stress level, and then heated until failure. Transient state tests were conducted on coupons, also extracted from $1 \mathrm{~mm}$ thick cold-rolled sheets and $6 \mathrm{~mm}$ thick hot-rolled sheets. Seventeen stress levels were examined, which ranged from $10 \%$ to $90 \%$ of the $0.2 \%$ proof (yield) stress at room temperature in increments of 5\%. At each stress level, two repeated tests were conducted, and a third test was added if there was a large disparity between any pairs of experimental results. In the transient state tests, a pre-specified tensile stress was firstly applied to the coupons and maintained using load control; the furnace temperature was then increased at a constant heating rate of $10{ }^{\circ} \mathrm{C} / \mathrm{min}$ until the specimen failed or the temperature reached $1000{ }^{\circ} \mathrm{C}$. Note that the total strain, measured from the extensometer, comprises two components - mechanical strain and thermal strain. Therefore, additional transient state tests with a small stress level of $4 \mathrm{MPa}$ (for straightening the coupon) were conducted to measure the thermal strains of the coupons at elevated temperatures; these thermal strains were then subtracted from the total strains measured from the anisothermal tests to exclude the influence of thermal expansion.

\section{Test results}

\subsection{Steady state test results}

The material stress-strain curves at elevated temperatures for the coupons extracted from coldrolled and hot-rolled sheets are shown in Figs 4(a) and 4(b), respectively. A step may be observed in each curve, which corresponds to the rapid change in the loading rate from 0.4 $\mathrm{mm} / \mathrm{min}$ to $15 \mathrm{~mm} / \mathrm{min}$. The temperature-dependent material properties were determined for 
each tensile coupon test, including the Young's modulus $E_{\theta}(\theta$ indicates the elevated temperature), the $0.2 \%$ proof stress $f_{0.2 p, \theta}$, the stress at $2 \%$ total strain $f_{y, \theta}$, the ultimate strength $f_{u, \theta}$, the strains $\left(\varepsilon_{0.2 p, \theta}\right.$ and $\left.\varepsilon_{2.0, \theta}\right)$ corresponding to $f_{0.2 p, \theta}$ and $f_{y, \theta}$, respectively, the ultimate strain $\varepsilon_{u, \theta}$ and the fracture strain $\varepsilon_{f, \theta}$; their definitions are illustrated in Fig. 5. Table 4 lists the measured values of the key material properties at room temperature. Note that the measured Young's modulus of the cold-rolled $1 \mathrm{~mm}$ thick material at room temperature was somewhat lower than that of hot-rolled $6 \mathrm{~mm}$ thick material; this is attributed, at least in part, to the influence of cold-work, which has been shown in previous studies [21,22] to cause a reduction in Young's modulus, but may also relate to errors associated with the testing of longitudinally curved coupons and the determination of the slope of stress-strain curves of materials with a low proportional limit. The reduction factors of the Young's modulus $\left(E_{\theta} / E\right), 0.2 \%$ proof stress $\left(f_{0.2 p, \theta} / f_{0.2 p}\right)$, stress at $2 \%$ total strain $\left(f_{y, \theta} / f_{0.2 p}\right)$, ultimate strength $\left(f_{u, \theta} / f_{u}\right)$, ultimate strain $\left(\varepsilon_{u, \theta} / \varepsilon_{u}\right)$ and fracture strain $\left(\varepsilon_{f, \theta} / \varepsilon_{f}\right)$ at each elevated temperature are reported in Table 5. The reduction factors for the material properties obtained from the steady state tests are also plotted against the temperature in Figs 6-10. EN 1993-1-2 [18] provides a formula for calculating the stress corresponding to $2 \%$ total strain $f_{y, \theta}$ at elevated temperatures, through the use of the $0.2 \%$ proof stress $f_{0.2 p, \theta}$ and the ultimate strength $f_{u, \theta}$, as given by Eq. (1), where $k_{2 \%, \theta}$ is a coefficient for the determination of $f_{y, \theta}$. Values of the $k_{2} \%, \theta$ coefficient were back-calculated based on the experimental results for $f_{0.2 p, \theta}, f_{y, \theta}$ and $f_{u, \theta}$ in Tables 4 and 5, and are plotted against the temperature in Fig. 11.

$$
f_{y, \theta}=f_{0.2 p, \theta}+k_{2 \%, \theta}\left(f_{u, \theta}-f_{0.2 p, \theta}\right)
$$




\subsection{Transient state test results}

The variation of thermal strain with temperature for the cold-rolled and hot-rolled materials was obtained from the thermal elongation tests, and is shown in Fig. 12. It was generally found that the thermal strain varied linearly with temperature up to $800{ }^{\circ} \mathrm{C}$, beyond which slightly nonlinear variation of thermal strain with temperature was observed, though this was attributed principally to some bowing of the coupons at higher temperatures. The EN 1993-1-2 thermal expansion curve [18] is also plotted in Fig. 12, and shown to slightly over-estimate the actual thermal strain of the new grade 1.4420 austenitic stainless steel. Upon deduction of the thermal strains from the total strains measured from the extensometer, the actual strain-temperature curves at various stress levels from the transient state tests were obtained, and are depicted in Fig. 13. The experimental data points with strain values corresponding to the same temperatures were then used to derive the elevated temperature stress-strain curves, as shown in Fig. 14, which can be employed to determine the temperature-dependent material properties. The derived reduction factors for the Young's modulus $\left(E_{\theta} / E\right)$ and $0.2 \%$ proof stress $\left(f_{0.2 p, \theta} / f_{0.2 p}\right)$, together with the $k_{2 \%, \theta}$ factor are also plotted in Figs 6, 8 and 11, respectively.

\section{Reduction factors at elevated temperatures}

\subsection{General}

In this section, the reduction factors for the key material properties at elevated temperatures, obtained from the steady and transient state tests, are compared with the corresponding reduction factors, given in the European code EN 1993-1-2 [18] and proposed by Gardner et al. [19]. Note that the mean values of the experimentally derived reduction factors at each elevated temperature level are used in the comparison, and are represented as curves passing 
through the corresponding mean test values for clarity purposes, as depicted in Figs 6-11. The mean reduction factors obtained from all the tests presented herein on grade 1.4420 austenitic stainless steel are given in Table 6; 'smoothed' versions of these values are given in Table 7 and are recommended for use when grade specific data are required. The European code EN 1993-1-2 [18] provides three sets of reduction factors for austenitic stainless steel grades 1.4301, 1.4401/4 and 1.4571, while Gardner et al. [19] collected material fire test data on seven austenitic stainless steel grades, placed them into three groups - austenitic I (1.4301, 1.4318 and 1.4818), austenitic II (1.4401, 1.4404 and 1.4541) and austenitic III (1.4571), based on the stability of the microstructure, and then proposed reduction factors for each group. The purpose of this was to rationalise the number of sets of reduction factors provided to structural engineers. Through initial investigations, it was generally found that the elevated temperature material properties of the new austenitic stainless steel grade 1.4420 are most similar to those for grade 1.4301 given in EN 1993-1-2 [18] and those for the austenitic I group proposed by Gardner et al. [19], both of which are thus presented and compared with the experimental results in Figs 6-11. Note that the reduction factors in EN 1993-1-2 [18] and Gardner et al. [19] are provided for discrete temperatures only, while the full range of each reduction curve was derived through the use of linear interpolation.

\subsection{Reduction factor for the $0.2 \%$ proof stress}

The reduction factors for the $0.2 \%$ proof stress $\left(f_{0.2 p, \theta} / f_{0.2 p}\right)$ obtained from both the steady and transient state tests, as well as the mean experimental values, are plotted with the corresponding reduction factor curves for grade 1.4301 given in EN 1993-1-2 [18] and for the austenitic I group proposed by Gardner et al. [19] in Fig. 6. It was generally found that both the discrepancy between the isothermal and anisothermal test results and the difference between the 
experimental results on cold-rolled and hot-rolled materials are rather small. The comparisons also indicate that the reduction factor curve proposed by Gardner et al. [19] provides an excellent representation of the mean values of the experimental reduction factors for the $0.2 \%$ proof stress, while the EN 1993-1-2 grade 1.4301 reduction factor curve [18] offers good agreement with the mean test values at high temperatures, but lies slightly above the mean value curve for temperatures from $200{ }^{\circ} \mathrm{C}$ to $600{ }^{\circ} \mathrm{C}$ (i.e. resulting in over-estimated $0.2 \%$ proof stresses). It is therefore recommended that the $0.2 \%$ proof stress reduction factors proposed by Gardner et al. [19] for the austenitic I group be employed for the new studied austenitic stainless steel grade, EN 1.4420.

\subsection{Reduction factor for the ultimate strength}

Fig. 7 displays the reduction factors for the ultimate strength $\left(f_{u, \theta} / f_{u}\right)$ obtained from the steady state tests, compared against the corresponding reduction factor curves given in EN 1993-1-2 [18] for grade 1.4301 and Gardner et al. [19] for the austenitic I group. As can be seen from Fig. 7, the reduction factors for the ultimate strength obtained from the tests on cold-rolled and hot-rolled materials are very similar. It may be seen that both the EN 1993-1-2 [18] and austenitic I group [19] reduction factor curves for the ultimate strength follow closely the trend but lie below the mean experimental values, and thus yield safe-sided predictions of the ultimate strength of grade 1.4420 at elevated temperatures. Compared to the ultimate strength reduction factor curve proposed by Gardner et al. [19], the corresponding reduction curve given in EN 1993-1-2 [18] follows more closely the mean experimental reduction factors for temperatures up to $600{ }^{\circ} \mathrm{C}$, thus providing more accurate predictions of $f_{u, \theta} / f_{u}$; for temperatures beyond $600{ }^{\circ} \mathrm{C}$, both reduction factor curves $[18,19]$ yield a similar level of conservatism. It is recommended that the reduction factors for the ultimate strength $\left(f_{u, \theta} / f_{u}\right)$, tabulated both in EN 
1993-1-2 [18] for grade 1.4301 stainless steel and in Gardner et al. [19] for the austenitic I group in [19], can be applied to the new austenitic stainless steel grade 1.4420 .

\subsection{Reduction factor for the modulus of elasticity}

The reduction factors for the modulus of elasticity $\left(E_{\theta} / E\right)$ obtained from both the isothermal and anisothermal tests are plotted in Fig. 8. The results are very scattered, as is often the case for modulus of elasticity measurements at elevated temperatures [17]; imperfect alignment of the thin tensile coupons and the use of a side-entry extensometer may have contributed to the measurement errors in this study. The EC3 reduction factor curve for the elastic modulus is also presented in Fig. 8, and shown to over-estimate the mean values of the experimental data for $E_{\theta} / E$ across almost the full temperature range. However, with the high level of scatter in the experimental data for Young's modulus found in this and previous studies, revised recommendations are considered to be not warranted at this stage, but further work is required to derive more reliable Young's modulus reduction factors.

\subsection{Reduction factor for the ultimate strain}

The reduction factors for the ultimate strain $\left(\varepsilon_{u, \theta} / \varepsilon_{u}\right)$ obtained from the steady state tests, together with their mean values, are plotted in Fig. 9; the reduction factor curves given in EN 1993-1-2 [18] for grade 1.4301 stainless steel and proposed in Gardner et al. [19] for the austenitic I group are also shown. The EC3 reduction factor curve may be generally seen to reflect accurately the mean values of the experimental data, whereas the reduction curve for the austenitic I group proposed by Gardner et al. [19] lies well below the mean test results. Use of either the grade 1.4301 reduction factors [18] or the grade specific reduction factors for 
$\varepsilon_{u, \theta} / \varepsilon_{u}$ given in Table 7 is therefore recommended for determining the ultimate strain of grade 1.4420 stainless steel at elevated temperatures.

\subsection{Reduction factor for the fracture strain}

Fig. 10 depicts the reduction factors for the fracture strain $\left(\varepsilon_{f, \theta} / \varepsilon_{f}\right)$, obtained from the steady state (isothermal) tests, together with the mean experimental values at each specified temperature. The reduction factors for the cold-rolled and hot-rolled materials are very consistent for temperatures up to $550{ }^{\circ} \mathrm{C}$, beyond which the hot-rolled specimens possess slightly higher values of $\varepsilon_{f, \theta} / \varepsilon f$. The mean reduction factors generally exhibit a decreasing trend for temperatures up to about $700{ }^{\circ} \mathrm{C}$, followed by a steeper increase at higher temperatures. The reduction factors for the austenitic I group [19] under-estimate the mean experimental values of $\varepsilon_{f, \theta} / \varepsilon_{f}$ for temperatures up to about $600^{\circ} \mathrm{C}$ but provide reasonable predictions thereafter. The smoothed mean value reduction factors given in Table 7 are recommended when accurate grade specific data is sought.

\subsection{Coefficient $k_{2 \%, \theta}$}

The values of the $k_{2 \%, \theta}$ coefficient at elevated temperatures were back-calculated based on both the isothermal and anisothermal test results, and then compared against those specified in EN 1993-1-2 [18] for grade 1.4301 and proposed by Gardner et al. [19] for the austenitic I group, as shown in Fig. 11. It was observed that the curve for predicting the $k_{2} \%, \theta$ coefficient given in EN 1993-1-2 [18] does not fully represent the trend of the mean test data, particularly at higher temperatures, while the curve of the $k_{2 \%, \theta}$ coefficient proposed by Gardner et al. [19] captures well the general distribution of the mean experimentally derived values. Note that the rapid 
change in the loading rate from $0.4 \mathrm{~mm} / \mathrm{min}$ to $15 \mathrm{~mm} / \mathrm{min}$ in the isothermal tests leads to a step in the stress-strain curves and higher ultimate stresses $f_{u, \theta}$ than those that would be derived from tests with a constant loading rate. An increase in the experimental values of $k_{2} \%, \theta$ would be expected if all the key material strengths (i.e. $f_{0.2 p, \theta}, f_{y, \theta}$ and $f_{u, \theta}$ ) were determined at the same testing speed. This would shift the data even closer to the curve of the $k_{2} \%, \theta$ coefficient proposed by Gardner et al. [19] for the austenitic I group.

\subsection{Summary}

Overall, the reduction factors for the $0.2 \%$ proof stress and ultimate strength and the $k_{2} \%, \theta$ coefficient, proposed by Gardner et al. [19] for the austenitic I group, match closely the experimentally derived reduction factors for the new grade 1.4420 austenitic stainless steel. For ultimate strain and fracture strain, the agreement was less good, particularly at lower temperatures. It should be noted that these reduction factors for the austenitic I group were based on a relatively small dataset, and it is recommended that these are reviewed in light of the newly available data. Regarding to the Young's modulus, further experimental investigations are required, since the obtained test data are rather scattered. For accurate grade specific reduction factors, the values given in Table 7 are recommended.

\section{Material modelling}

In this section, the two-stage Ramberg-Osgood material model [19,22-27] given by Eq. (2) is employed to represent the elevated temperature stress-strain response of the new grade 1.4420 austenitic stainless steel, where $E_{0.2 \mathrm{p}, \theta}$ and $\varepsilon_{0.2 \mathrm{p}, \theta}$ are the tangent modulus and the total strain corresponding to the $0.2 \%$ proof stress at elevated temperature, respectively, and $n_{\theta}$ and $m_{\theta}$ are 
the strain hardening exponents used for the first and second stages of the material model, respectively. The first stage of the material model adopts the original Ramberg-Osgood expression $[23,24]$ up to the $0.2 \%$ proof stress, but based on elevated temperature material properties, while the second stage of the model extends from the $0.2 \%$ proof stress to the ultimate tensile stress. The second stage of the model can be forced to pass through the elevated temperature stress at $2 \%$ total strain $f_{y, \theta}$, which is readily available in structural fire design [19], by adopting the definition of $m_{\theta}$ given by Eq. (3). This is illustrated in Fig. 15.

$$
\varepsilon=\left\{\begin{array}{cc}
\frac{\sigma}{E_{\theta}}+0.002\left(\frac{\sigma}{f_{0.2 p, \theta}}\right)^{n_{\theta}} & \sigma \leq f_{0.2 p, \theta} \\
\frac{\sigma-f_{0.2 p, \theta}}{E_{0.2 p, \theta}}+\varepsilon_{u, \theta}\left(\frac{\sigma-f_{0.2 p, \theta}}{f_{u, \theta}-f_{0.2 p, \theta}}\right)^{m_{\theta}}+\varepsilon_{0.2 p, \theta} & f_{0.2 p, \theta}<\sigma \leq f_{u, \theta}
\end{array}\right.
$$

$$
m_{\theta}=\frac{\ln \left(\frac{\varepsilon_{u, \theta}}{0.02-\varepsilon_{0.2 p, \theta}-\frac{f_{y, \theta}-f_{0.2 p, \theta}}{E_{0.2 p, \theta}}}\right)}{\ln \left(\frac{f_{u, \theta}-f_{0.2 p, \theta}}{f_{y, \theta}-f_{0.2 p, \theta}}\right)}
$$

A similar approach can be applied at room temperature, whereby the second stage of the Ramberg-Osgood model given in Annex C of EN 1993-1-4 [28] can be forced to pass through the $1 \%$ proof stress $f_{1.0 p}$, which is a value that is often reported in experimental studies and by manufacturers, by adopting the definition of $m$ given by Eq. (4). This is illustrated in Fig. 16.

$$
m=\frac{\ln \left(\frac{\varepsilon_{u}}{0.01+\frac{f_{1.0 p}}{E}-\varepsilon_{0.2 p}-\frac{f_{1.0 p}-f_{0.2 p}}{E_{0.2 p}}}\right)}{\ln \left(\frac{f_{u}-f_{0.2 p}}{f_{1.0 p}-f_{0.2 p}}\right)}
$$


Comparisons of the two-stage Ramberg-Osgood material model with the measured elevated temperature stress-strain curves are shown in Fig. 17, indicating excellent agreement.

\section{Conclusions}

An experimental investigation of the elevated temperature material properties of a new grade 1.4420 austenitic stainless steel has been presented. A total of 164 material tensile coupon tests were performed, including 80 steady state tests with the temperatures ranging from $25{ }^{\circ} \mathrm{C}$ to $1100{ }^{\circ} \mathrm{C}$ and 84 transient state tests with the stress levels ranging from $10 \%$ to $90 \%$ of the $0.2 \%$ proof stress at room temperature. The tensile coupons were extracted from both $1 \mathrm{~mm}$ thick cold-rolled sheets and $6 \mathrm{~mm}$ thick hot-rolled sheets. The experimentally derived reduction factors for the key material properties at elevated temperatures were then compared with those given in EN 1993-1-2 [18] for grade 1.4301 and proposed by Gardner et al. [19] for the austenitic I group. The reduction factors for the $0.2 \%$ proof stress and ultimate strength and the $k_{2 \%, \theta}$ coefficient, proposed by Gardner et al. [19] for the austenitic I group, were found to be applicable to grade 1.4420 stainless steel, while those for the ultimate and fracture strains were less accurate, particularly at low temperatures. Grade specific elevated temperature reduction factors for all the key material properties were provided in Table 7. Finally, a two-stage Ramberg-Osgood material model [19] was used to represent the elevated temperature stressstrain response of the new stainless steel grade, and shown to provide good agreement with the experimental data. 


\section{References}

[1] Afshan S, Gardner L. The continuous strength method for structural stainless steel design. Thin-Walled Structures, 2013;68(4):42-49.

[2] Zhao O, Rossi B, Gardner L, Young B. Behaviour of structural stainless steel cross-sections under combined loading - Part II: Numerical modelling and design approach. Engineering Structures, 2015;89:247-259.

[3] Liew A, Gardner L. Ultimate capacity of structural steel cross-sections under compression, bending and combined loading. Structures, 2015;1:2-11.

[4] Zhao O, Gardner L, Young B. Structural performance of stainless steel circular hollow sections under combined axial load and bending - Part 2: Parametric studies and design. ThinWalled Structures, 2016;101:240-248.

[5] Zhao O, Gardner L, Young B. Behaviour and design of stainless steel SHS and RHS beamcolumns. Thin-Walled Structures, 2016;106:330-345.

[6] Buchanan C, Gardner L, Liew A. The continuous strength method for the design of circular hollow sections. Journal of Constructional Steel Research, 2016;118:207-216.

[7] Zhao O, Rossi B, Gardner L, Young B. Experimental and numerical studies of ferritic stainless steel tubular cross-sections under combined compression and bending. Journal of Structural Engineering (ASCE), 2016;142(2):04015110.

[8] Zhao O, Afshan S, Gardner L. Structural response and continuous strength method design of slender stainless steel cross-sections. Engineering Structures, 2017;140:14-25. 
[9] Zhao O, Gardner L. Design of non-doubly symmetric stainless steel sections in bending. Journal of Constructional Steel Research, submitted.

[10] EN 10028-7:2016. Flat products made of steels for pressure purposes - Part 7: Stainless steels. CEN; 2016.

[11] Signorelli R, Wegrelius L, Ohligschläger T. Corrosion resistance of Supra 316plus - a comparison with 1.4404 and 1.4432. In: Proceeding of 9th European Stainless Steel Conference \& 5th European Duplex Stainless Steel Conference: 2017 May 25-27; Bergamo (Italy). Milano: Associazione Italiana di Metallurgia; 2017.

[12] Kouhi J, Talja A, Salmi P, Ala-Outinen T. Current R\&D work on the use of stainless steel in construction in Finland. Journal of Constructional Steel Research, 2000;54(1):31-50.

[13] Gardner L, and Baddoo NR. Fire testing and design of stainless steel structures. Journal of Constructional Steel Research, 2006;62(6): 532-543.

[14] Chen J, Young B. Stress-strain curves for stainless steel at elevated temperatures. Engineering Structures, 2006;28(2): 229-239.

[15] Huang Y, Young B. Stress-strain relationship of cold-formed lean duplex stainless steel at elevated temperatures. Journal of Constructional Steel Research, 2014;92:103-113.

[16] Manninen T, Säynäjäkangas J. Mechanical properties of ferritic stainless steels at elevated temperature. In Proceedings of the Fourth International Experts Seminar on Stainless Steel in Structures, 2012. 
[17] Gardner L, Bu Y, Francis P, Baddoo NR, Cashell KA, McCann F. Elevated temperature material properties of stainless steel reinforcing bar. Construction and Building Materials, 2016;114:977-997.

[18] EN 1993-1-2. Eurocode 3: Design of steel structures - Part 1.2: General rules structural fire design. CEN; 2005.

[19] Gardner L, Insausti A, Ng KT, Ashraf M. Elevated temperature material properties of stainless steel alloys. Journal of Constructional Steel Research, 2010;66(5):634-647.

[20] EN 10002-5. Metallic materials - Tensile testing - Part 5: Method of testing at elevated temperature. CEN; 1992.

[21] Gardner L, Saari N, Wang F. Comparative experimental study of hot-rolled and coldformed rectangular hollow sections. Thin-Walled Structures, 2010;48(7),495-507.

[22] Arrayago I, Real E, Gardner L. Description of stress-strain curves for stainless steel alloys. Materials \& Design, 2015;87,540-552.

[23] Ramberg W, Osgood WR. Description of stress-strain curves by three parameters. Technical note No 902, Washington DC: National advisory committee for aeronautics. 1943.

[24] Hill HN. Determination of stress-strain relations from offset yield strength values. Technical note No 927, Washington DC: National advisory committee for aeronautics. 1944.

[25] Mirambell E, Real E. On the calculation of deflections in structural stainless steel beams: An experimental and numerical investigation. Journal of Constructional Steel Research, 2000;54(1):109-133. 
[26] Rasmussen KJR. Full-range stress-strain curves for stainless steel alloys. Journal of Constructional Steel Research, 2003;59(1):47-61.

[27] Gardner L, Ashraf M. Structural design for non-linear metallic materials. Engineering Structures, 2006;28(6):926-934.

[28] EN 1993-1-4:2006+A1:2015. Eurocode 3: Design of steel structures - Part 1.4: General rules - Supplementary rules for stainless steels, including amendment A1 (2015). Brussels: European Committee for Standardization (CEN); 2015. 
Table 1 Nominal mechanical properties of grade 1.4420 stainless steel specified in EN 10028-7:2016 [10].

\begin{tabular}{cccc}
\hline Product form & $\begin{array}{c}f_{0.2 p} \\
(\mathrm{MPa})\end{array}$ & $\begin{array}{c}f_{1.0 p} \\
(\mathrm{MPa})\end{array}$ & $\begin{array}{c}f_{u} \\
(\mathrm{MPa})\end{array}$ \\
\hline Cold-rolled strip & 350 & 380 & $650-850$ \\
Hot-rolled strip & 350 & 380 & $650-850$ \\
Hot-rolled plate & 320 & 350 & $630-830$ \\
\hline
\end{tabular}

Table 2 Typical chemical composition of grade 1.4420 stainless steel.

\begin{tabular}{cccccc}
\hline Grade & $\mathrm{C}(\%)$ & $\mathrm{Cr}(\%)$ & $\mathrm{Ni}(\%)$ & $\mathrm{Mo}(\%)$ & $\mathrm{N}(\%)$ \\
\hline EN 1.4420 & 0.02 & 20.3 & 8.6 & 0.7 & 0.19 \\
\hline
\end{tabular}

Table 3 Summary of elevated temperature material tests.

\begin{tabular}{cccc}
\hline Testing method & Sheet material & Nominal thickness $(\mathrm{mm})$ & Number of tests \\
\hline \multirow{2}{*}{ Steady state tests } & Cold-rolled & 1.0 & 42 \\
& Hot-rolled & 6.0 & 38 \\
\hline \multirow{2}{*}{ Transient state tests } & Cold-rolled & 1.0 & 44 \\
& Hot-rolled & 6.0 & 40 \\
\hline
\end{tabular}

Table 4 Material properties at room temperature $\left(25^{\circ} \mathrm{C}\right)$.

\begin{tabular}{ccccccccc}
\hline Sheet material & \multirow{2}{*}{ Nominal thickness $(\mathrm{mm})$} & $\begin{array}{c}E \\
(\mathrm{GPa})\end{array}$ & $\begin{array}{c}f_{0.2 p} \\
(\mathrm{MPa})\end{array}$ & $\begin{array}{c}f_{1.0 p} \\
(\mathrm{MPa})\end{array}$ & $\begin{array}{c}f_{2.0} \\
(\mathrm{MPa})\end{array}$ & $\begin{array}{c}f_{u} \\
(\mathrm{MPa})\end{array}$ & $\begin{array}{c}\varepsilon_{u} \\
(\%)\end{array}$ & $\begin{array}{c}\varepsilon_{f} \\
(\%)\end{array}$ \\
\hline Cold-rolled & 1.0 & 174.5 & 410 & 451 & 474 & 740 & 25.4 & 42.0 \\
Hot-rolled & 6.0 & 227.0 & 358 & 406 & 429 & 689 & 25.8 & 48.0 \\
\hline
\end{tabular}


Table 5 Reduction factors for EN 1.4420 material properties from steady state tests.

(a) $1 \mathrm{~mm}$ thick cold-rolled material

\begin{tabular}{|c|c|c|c|c|c|c|}
\hline$\theta\left({ }^{\circ} \mathrm{C}\right)$ & $E_{\theta} / E$ & $f_{0.2 p, \theta} / f_{0.2 p}$ & $f_{y, \theta} / f_{0.2 p}$ & $f_{u, \theta} / f_{u}$ & $\varepsilon_{u, \theta} / \varepsilon_{u}$ & $\varepsilon_{f, \theta} / \varepsilon_{f}$ \\
\hline $100-1$ & 0.92 & 0.83 & 0.93 & 0.87 & 1.10 & 1.07 \\
\hline $100-2$ & 0.92 & 0.83 & 0.95 & 0.88 & 1.10 & 1.02 \\
\hline $200-1$ & 0.89 & 0.71 & 0.81 & 0.78 & 1.09 & 0.95 \\
\hline $200-2$ & 0.69 & 0.69 & 0.80 & 0.78 & 1.09 & 0.98 \\
\hline $300-1$ & 0.93 & 0.63 & 0.74 & 0.75 & 1.04 & 0.86 \\
\hline $300-2$ & 0.57 & 0.62 & 0.74 & 0.75 & 1.06 & 0.86 \\
\hline $400-1$ & 0.69 & 0.57 & 0.68 & 0.73 & 1.08 & 0.88 \\
\hline $400-2$ & 0.81 & 0.58 & 0.70 & 0.73 & 1.08 & 0.88 \\
\hline $500-1$ & 0.91 & 0.56 & 0.65 & 0.69 & 1.06 & 0.88 \\
\hline $500-2$ & 0.38 & 0.54 & 0.63 & 0.68 & 1.05 & 0.88 \\
\hline $500-3$ & 0.72 & 0.53 & 0.62 & 0.68 & 1.04 & 0.86 \\
\hline $550-1$ & 0.38 & 0.53 & 0.60 & 0.65 & 0.95 & 0.76 \\
\hline $550-2$ & 0.38 & 0.52 & 0.62 & 0.64 & 0.88 & 0.74 \\
\hline $600-1$ & 0.79 & 0.51 & 0.60 & 0.62 & 0.64 & 0.52 \\
\hline $600-2$ & 0.72 & 0.51 & 0.61 & 0.62 & 0.65 & 0.57 \\
\hline $650-1$ & 0.55 & 0.49 & 0.60 & 0.58 & 0.58 & 0.50 \\
\hline $650-2$ & 0.86 & 0.48 & 0.58 & 0.57 & 0.61 & 0.52 \\
\hline $700-1$ & 0.35 & 0.48 & 0.57 & 0.50 & 0.47 & 0.48 \\
\hline $700-2$ & 0.50 & 0.48 & 0.58 & 0.50 & 0.46 & 0.48 \\
\hline $750-1$ & 0.68 & 0.42 & 0.52 & 0.43 & 0.43 & 0.55 \\
\hline $750-2$ & 0.60 & 0.43 & 0.53 & 0.44 & 0.46 & 0.57 \\
\hline $750-3$ & 0.55 & 0.44 & 0.53 & 0.45 & 0.45 & 0.52 \\
\hline $800-1$ & 0.46 & 0.35 & 0.40 & 0.36 & 0.50 & 0.67 \\
\hline $800-2$ & 0.42 & 0.36 & 0.36 & 0.37 & 0.53 & 0.62 \\
\hline $800-3$ & 0.38 & 0.34 & 0.38 & 0.35 & 0.49 & 0.74 \\
\hline $850-1$ & 0.32 & 0.28 & 0.28 & 0.26 & 0.41 & 0.74 \\
\hline $850-2$ & 0.24 & 0.27 & 0.26 & 0.26 & 0.42 & 0.67 \\
\hline $850-3$ & 0.29 & 0.28 & 0.28 & 0.27 & 0.39 & 0.79 \\
\hline $900-1$ & 0.31 & 0.20 & 0.18 & 0.20 & 0.44 & 0.76 \\
\hline $900-2$ & 0.21 & 0.20 & 0.18 & 0.20 & 0.38 & 0.76 \\
\hline $950-1$ & 0.26 & 0.14 & 0.12 & 0.14 & 0.51 & 0.98 \\
\hline $950-2$ & 0.20 & 0.16 & 0.14 & 0.17 & 0.48 & 0.93 \\
\hline $950-3$ & 0.28 & 0.14 & 0.12 & 0.15 & 0.41 & 0.90 \\
\hline $1000-1$ & 0.25 & 0.10 & 0.09 & 0.12 & 0.61 & 0.98 \\
\hline $1000-2$ & 0.17 & 0.09 & 0.09 & 0.12 & 0.62 & 1.05 \\
\hline $1050-1$ & 0.21 & 0.07 & 0.07 & 0.09 & 0.58 & 1.10 \\
\hline $1050-2$ & 0.19 & 0.06 & 0.06 & 0.09 & 0.56 & 1.12 \\
\hline $1100-1$ & 0.19 & 0.05 & 0.05 & 0.07 & 0.52 & - \\
\hline $1100-2$ & 0.10 & 0.05 & 0.04 & 0.07 & 0.64 & - \\
\hline
\end{tabular}


(b) $6 \mathrm{~mm}$ thick hot-rolled material

\begin{tabular}{|c|c|c|c|c|c|c|}
\hline$\theta\left({ }^{\circ} \mathrm{C}\right)$ & $E_{\theta} / E$ & $f_{0.2 p, \theta} f_{0.2 p}$ & $f_{y, \theta} / f_{0.2 p}$ & $f_{u, \theta} / f_{u}$ & $\varepsilon_{u, \theta} / \varepsilon_{u}$ & $\varepsilon_{f, \theta} / \varepsilon_{f}$ \\
\hline $100-1$ & 0.96 & 0.81 & 1.01 & 0.90 & 1.01 & 1.02 \\
\hline $100-2$ & 0.94 & 0.83 & 1.06 & 0.89 & 0.97 & 0.98 \\
\hline $200-1$ & 0.80 & 0.68 & 0.87 & 0.81 & 0.99 & 0.88 \\
\hline $200-2$ & 0.55 & 0.62 & 0.79 & 0.76 & 1.01 & 0.92 \\
\hline $200-3$ & 0.54 & 0.64 & 0.83 & 0.80 & 1.01 & 0.94 \\
\hline $300-1$ & 0.45 & 0.61 & 0.78 & 0.77 & 1.01 & 0.83 \\
\hline $300-2$ & 0.44 & 0.60 & 0.76 & 0.76 & 1.00 & 0.83 \\
\hline $400-1$ & 0.43 & 0.53 & 0.71 & 0.74 & 1.03 & 0.85 \\
\hline $400-2$ & 0.43 & 0.55 & 0.72 & 0.74 & 1.06 & 0.85 \\
\hline $500-1$ & 0.45 & 0.52 & 0.70 & 0.70 & 0.98 & 0.83 \\
\hline $500-2$ & 0.33 & 0.50 & 0.68 & 0.71 & 1.02 & 0.83 \\
\hline $550-1$ & 0.51 & 0.48 & 0.63 & 0.66 & 0.91 & 0.77 \\
\hline $550-2$ & 0.20 & 0.51 & 0.63 & 0.67 & 0.93 & 0.77 \\
\hline $600-1$ & 0.73 & 0.48 & 0.64 & 0.66 & 0.83 & 0.71 \\
\hline $600-2$ & 0.51 & 0.47 & 0.62 & 0.66 & 0.83 & 0.69 \\
\hline $650-1$ & 0.47 & 0.48 & 0.64 & 0.61 & 0.74 & 0.69 \\
\hline $650-2$ & 0.52 & 0.49 & 0.65 & 0.60 & 0.76 & 0.69 \\
\hline $700-1$ & 0.55 & 0.45 & 0.59 & 0.53 & 0.67 & 0.69 \\
\hline $700-2$ & 0.49 & 0.46 & 0.60 & 0.53 & 0.72 & 0.73 \\
\hline $750-1$ & 0.46 & 0.43 & 0.54 & 0.46 & 0.71 & 0.83 \\
\hline $750-2$ & 0.63 & 0.42 & 0.54 & 0.46 & 0.72 & 0.83 \\
\hline $800-1$ & 0.50 & 0.36 & 0.44 & 0.38 & 0.70 & 0.92 \\
\hline $800-2$ & 0.80 & 0.35 & 0.42 & 0.37 & 0.79 & 0.98 \\
\hline $850-1$ & 0.56 & 0.29 & 0.32 & 0.30 & 0.66 & 1.06 \\
\hline $850-2$ & 0.44 & 0.30 & 0.33 & 0.30 & 0.67 & 1.13 \\
\hline $900-1$ & 0.40 & 0.21 & 0.22 & 0.23 & 0.59 & 1.17 \\
\hline $900-2$ & 0.38 & 0.22 & 0.23 & 0.22 & 0.55 & 1.17 \\
\hline $950-1$ & 0.32 & 0.15 & 0.15 & 0.16 & 0.58 & 1.27 \\
\hline $950-2$ & 0.31 & 0.16 & 0.16 & 0.17 & 0.59 & 1.31 \\
\hline $1000-1$ & 0.25 & 0.11 & 0.11 & 0.13 & 0.62 & 1.50 \\
\hline $1000-2$ & 0.26 & 0.11 & 0.11 & 0.12 & 0.63 & 1.50 \\
\hline $1050-1$ & 0.22 & 0.08 & 0.08 & 0.10 & 0.50 & 1.63 \\
\hline $1050-2$ & 0.24 & 0.08 & 0.08 & 0.10 & 0.66 & 1.60 \\
\hline $1100-1$ & 0.25 & 0.06 & 0.06 & 0.07 & 0.56 & 1.73 \\
\hline $1100-2$ & 0.21 & 0.06 & 0.06 & 0.08 & 0.54 & 1.85 \\
\hline
\end{tabular}


Table 6 Mean test values of reduction factors for grade 1.4420 stainless steel.

\begin{tabular}{ccccccccccccc}
\hline \multirow{2}{*}{ Reduction factor } & \multicolumn{10}{c}{ Temperature $\theta\left({ }^{\circ} \mathrm{C}\right)$} \\
\cline { 2 - 12 } & 100 & 200 & 300 & 400 & 500 & 600 & 700 & 800 & 900 & 1000 & 1100 \\
\hline$f_{0.2 p, \theta} / f_{0.2 p}$ & 0.81 & 0.67 & 0.60 & 0.55 & 0.52 & 0.48 & 0.45 & 0.34 & 0.21 & 0.10 & 0.05 \\
$f_{u, \theta} / f_{u}$ & 0.88 & 0.79 & 0.76 & 0.74 & 0.69 & 0.64 & 0.52 & 0.37 & 0.21 & 0.12 & 0.07 \\
$E_{\theta} / E$ & 0.90 & 0.72 & 0.60 & 0.55 & 0.51 & 0.59 & 0.41 & 0.44 & 0.32 & 0.23 & 0.19 \\
$\varepsilon_{u, \theta} / \varepsilon_{u}$ & 1.05 & 1.04 & 1.02 & 1.06 & 1.03 & 0.74 & 0.58 & 0.60 & 0.49 & 0.62 & 0.55 \\
$\varepsilon_{f, \theta} / \varepsilon_{f}$ & 1.02 & 0.93 & 0.85 & 0.87 & 0.86 & 0.62 & 0.59 & 0.78 & 0.96 & 1.26 & 1.79 \\
$k_{2 \%, \theta}$ & 0.19 & 0.24 & 0.24 & 0.22 & 0.21 & 0.23 & 0.27 & 0.18 & 0.04 & 0.01 & 0.01 \\
\hline
\end{tabular}

Table 7 Recommended grade specific reduction factors for EN 1.4420 stainless steel based on 'smoothed' mean test data.

\begin{tabular}{ccccccccccccc}
\hline $\begin{array}{c}\text { Reduction } \\
\text { factor }\end{array}$ & 20 & 100 & 200 & 300 & 400 & 500 & 600 & 700 & 800 & 900 & 1000 & 1100 \\
\hline & 20 & 0.81 & 0.67 & 0.60 & 0.55 & 0.52 & 0.48 & 0.45 & 0.34 & 0.21 & 0.10 & 0.05 \\
\hline$f_{0.2 p, \theta} / f_{0.2 p}$ & 1.00 & 0.0 .12 & 0.07 \\
$f_{u, \theta} / f_{u}$ & 1.00 & 0.88 & 0.79 & 0.76 & 0.74 & 0.69 & 0.64 & 0.52 & 0.37 & 0.21 & 0.12 & 0.07 \\
$E_{\theta} / E$ & - & - & - & - & - & - & - & - & - & - & - & - \\
$\varepsilon_{u, \theta} / \varepsilon_{u}$ & 1.00 & 1.00 & 1.00 & 1.00 & 1.00 & 1.00 & 0.74 & 0.58 & 0.53 & 0.49 & 0.54 & 0.59 \\
$\varepsilon_{f, \theta} / \varepsilon_{f}$ & 1.00 & 1.00 & 0.93 & 0.86 & 0.86 & 0.86 & 0.72 & 0.59 & 0.77 & 0.96 & 1.26 & 1.79 \\
$k_{2 \%, \theta}$ & 0.20 & 0.20 & 0.20 & 0.20 & 0.20 & 0.20 & 0.23 & 0.27 & 0.15 & 0.04 & 0.01 & 0.01 \\
\hline
\end{tabular}
Note: 'smoothed' values of the reduction factors for the $0.2 \%$ proof stress $\left(f_{0.2 p, \theta} / f_{0.2 p}\right)$ and the ultimate strength $\left(f_{u, \theta} / f_{u}\right)$ are taken as the mean test values; therefore, the corresponding 'smoothed' values are not shown in Figs 6 and 7. 


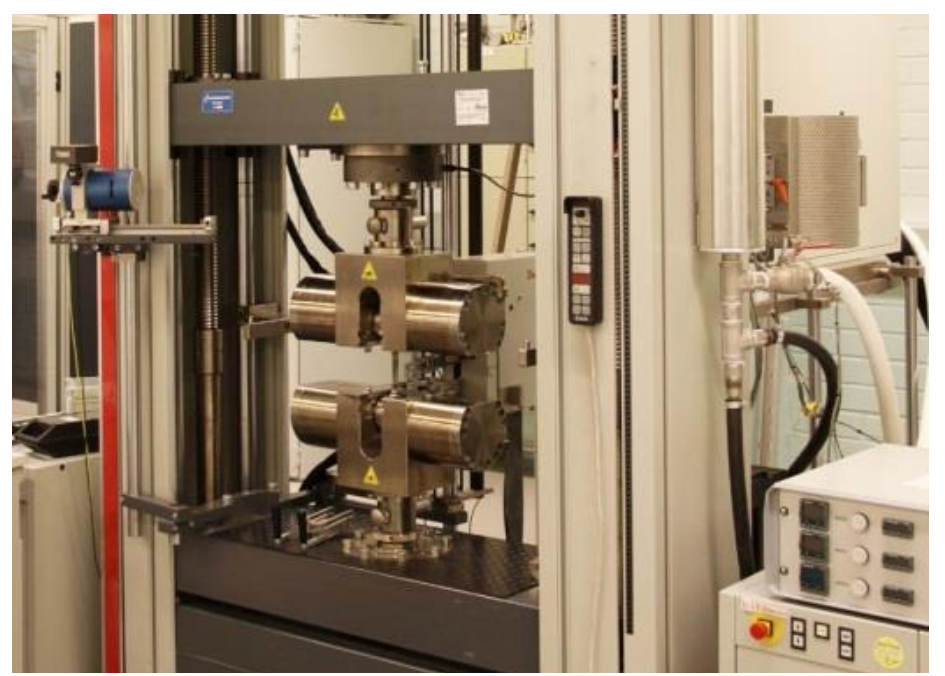

Fig. 1. Tensile testing machine.

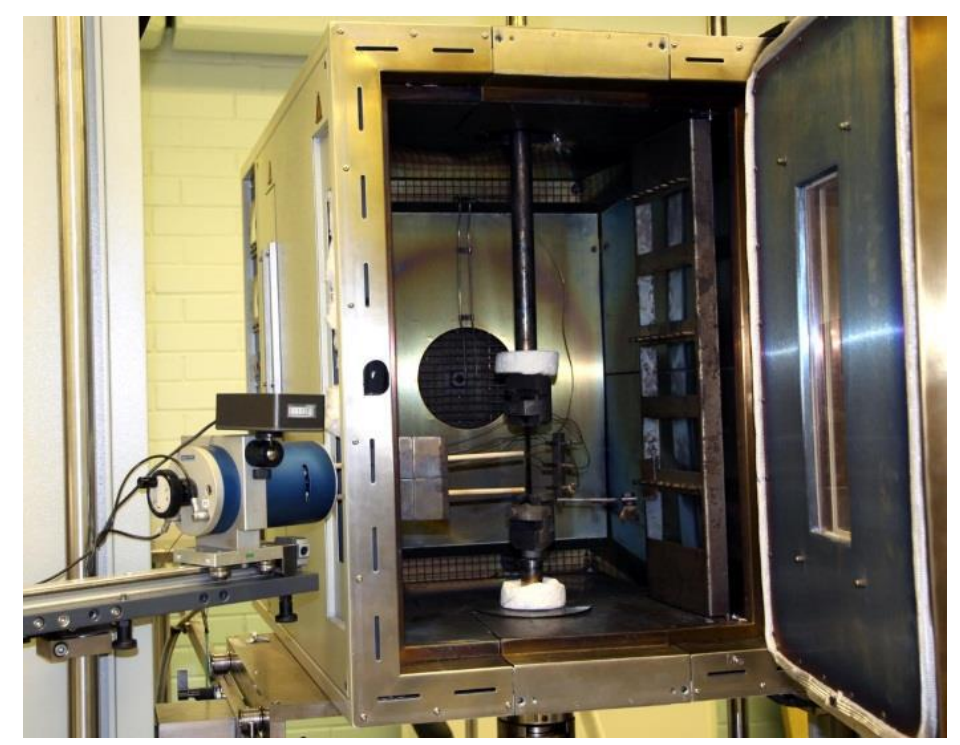

Fig. 2. Environmental chamber. 


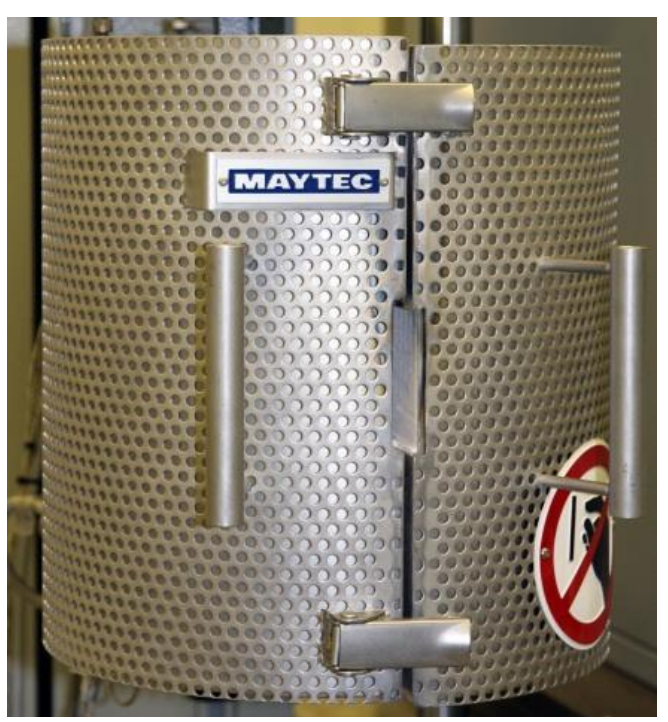

Fig. 3. High temperature furnace. 


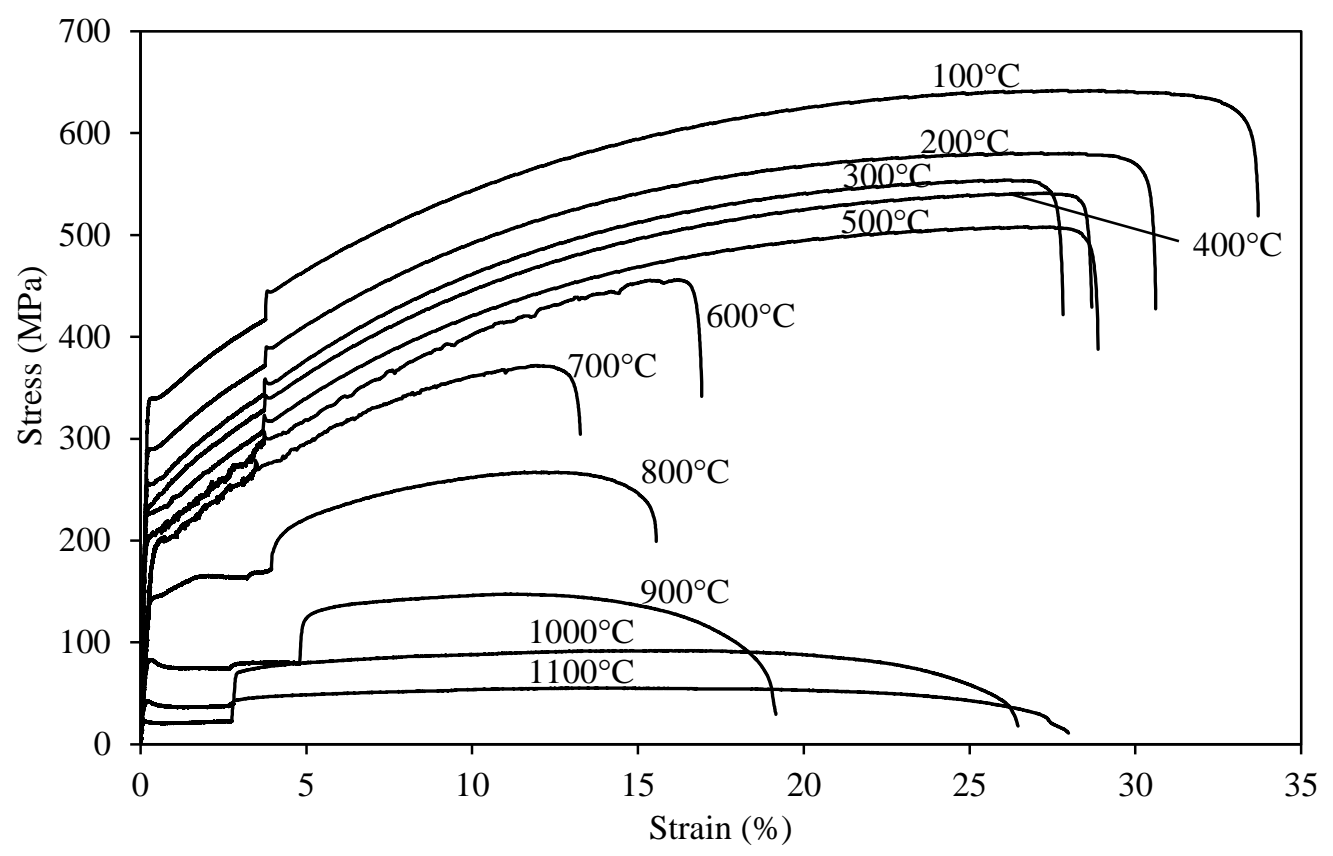

(a) Cold-rolled specimens

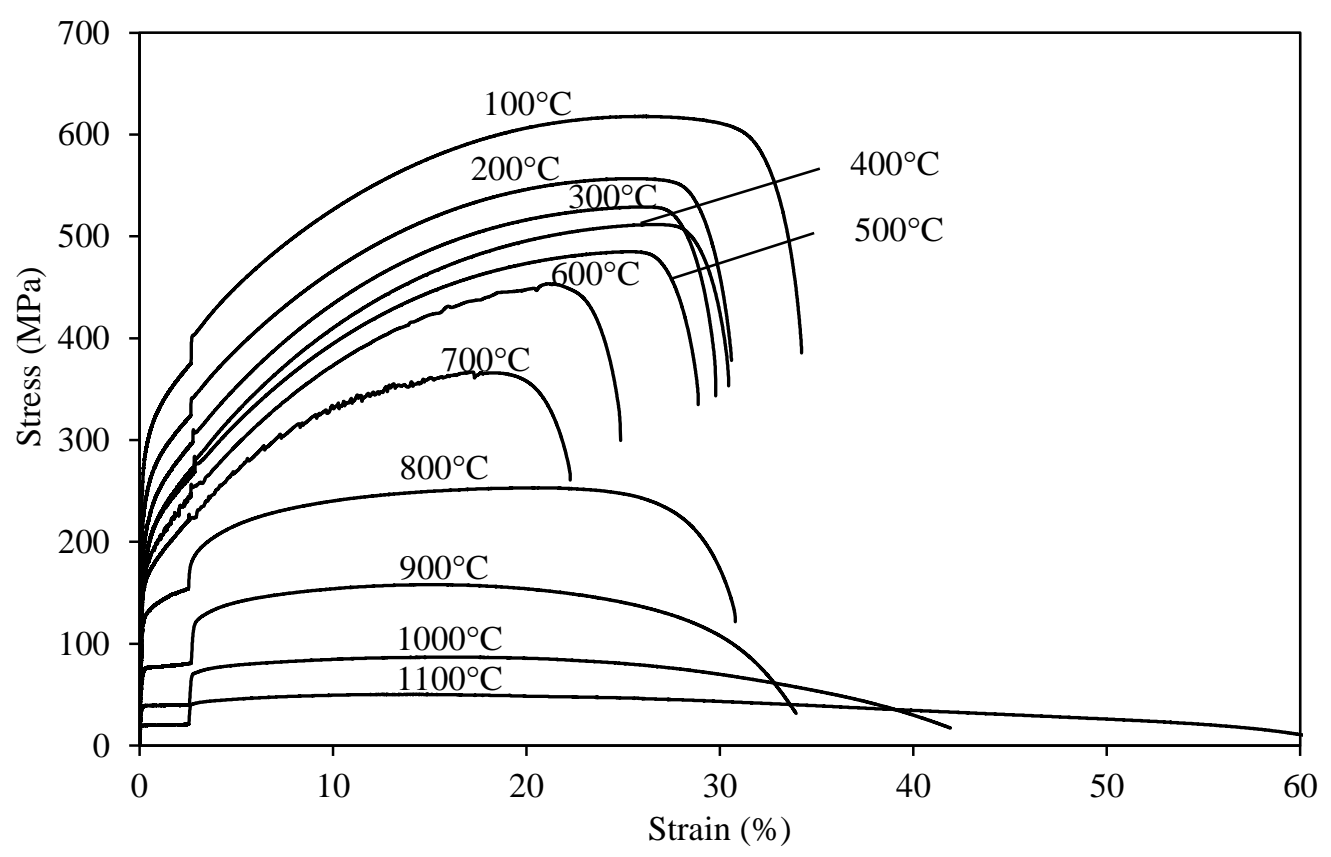

(b) Hot-rolled specimens

Fig. 4. Stress-strain curves at elevated temperatures measured from steady state tests. 


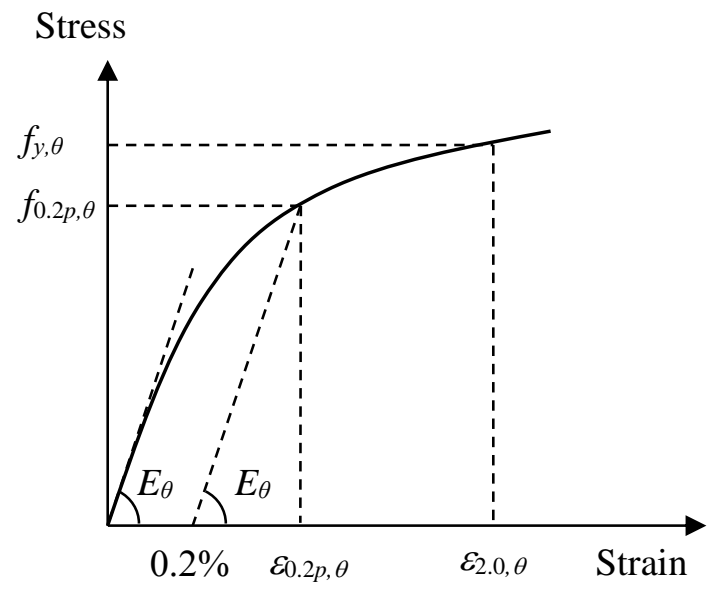

(a) Initial portion of stress-strain curve

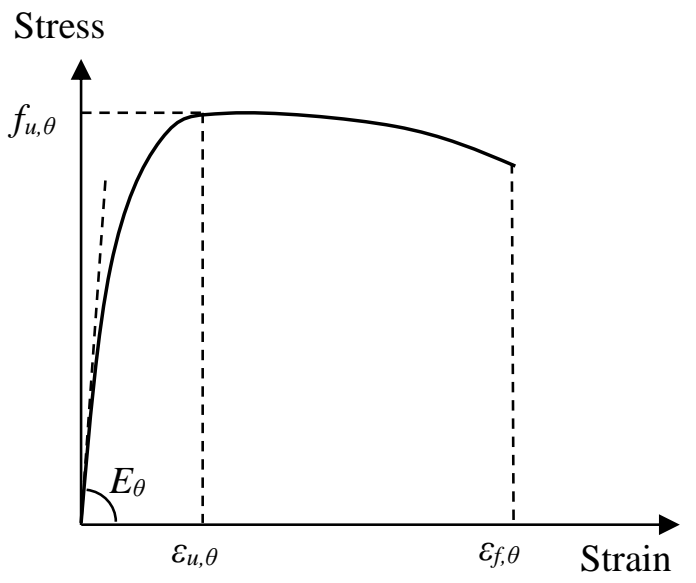

(b) Full stress-strain curve

Fig. 5. Definition of material properties at elevated temperature.

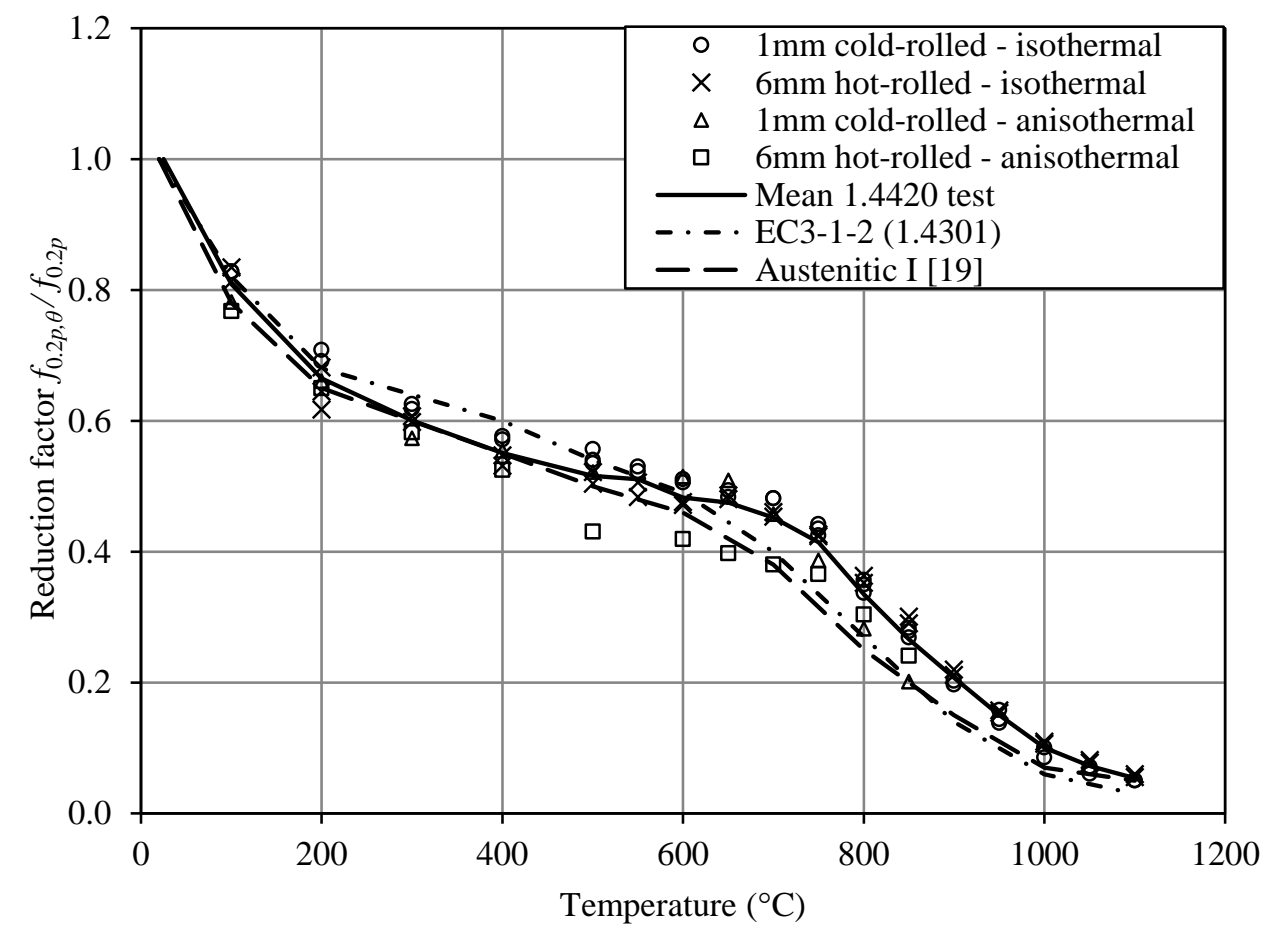

Fig. 6. Reduction factors for $0.2 \%$ proof strength $\left(f_{0.2 p, \theta} / f_{0.2 p}\right)$ at elevated temperatures, compared with design values. 


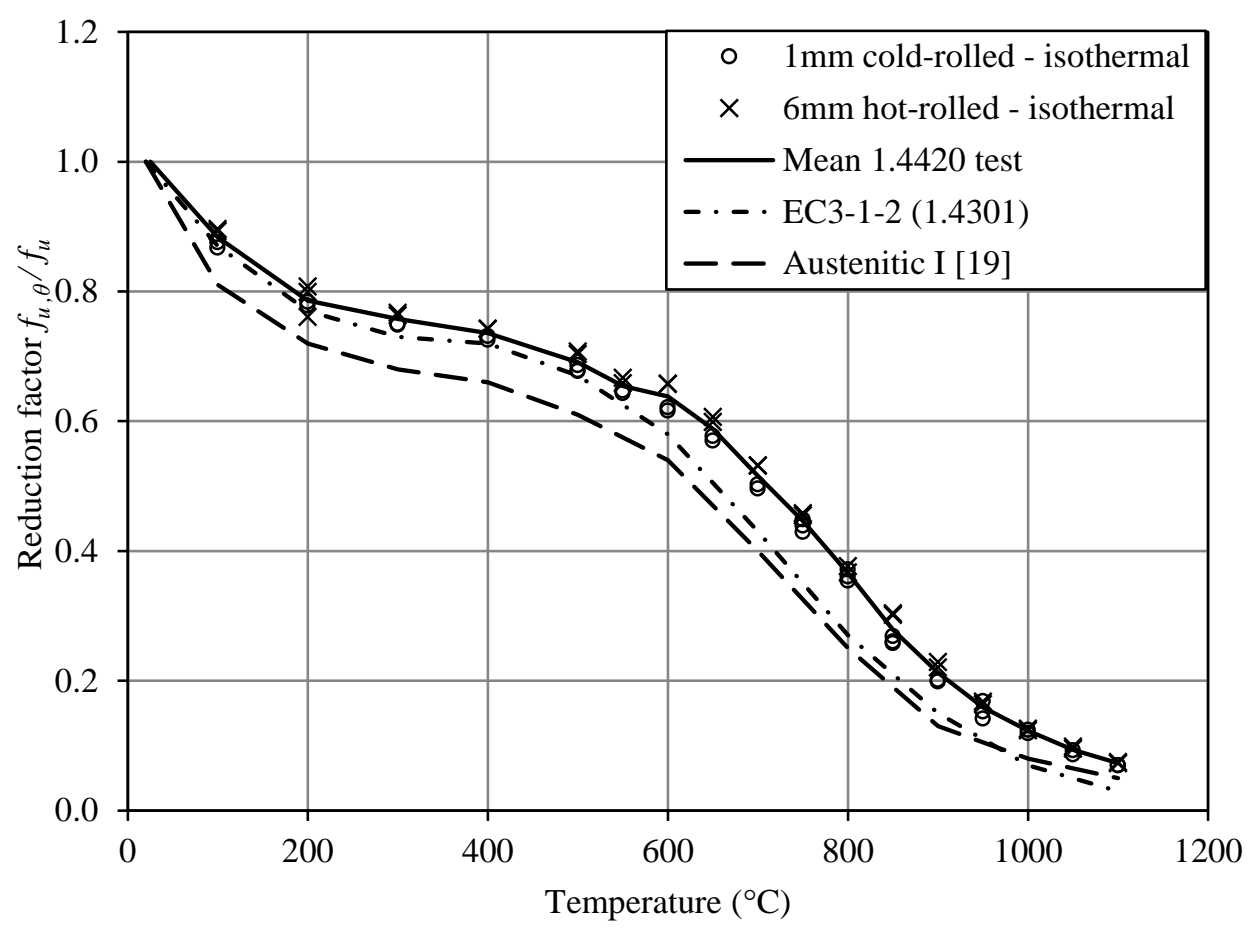

Fig. 7. Reduction factors for ultimate tensile strength $\left(f_{u, \theta} / f_{u}\right)$ at elevated temperatures, compared with design values.

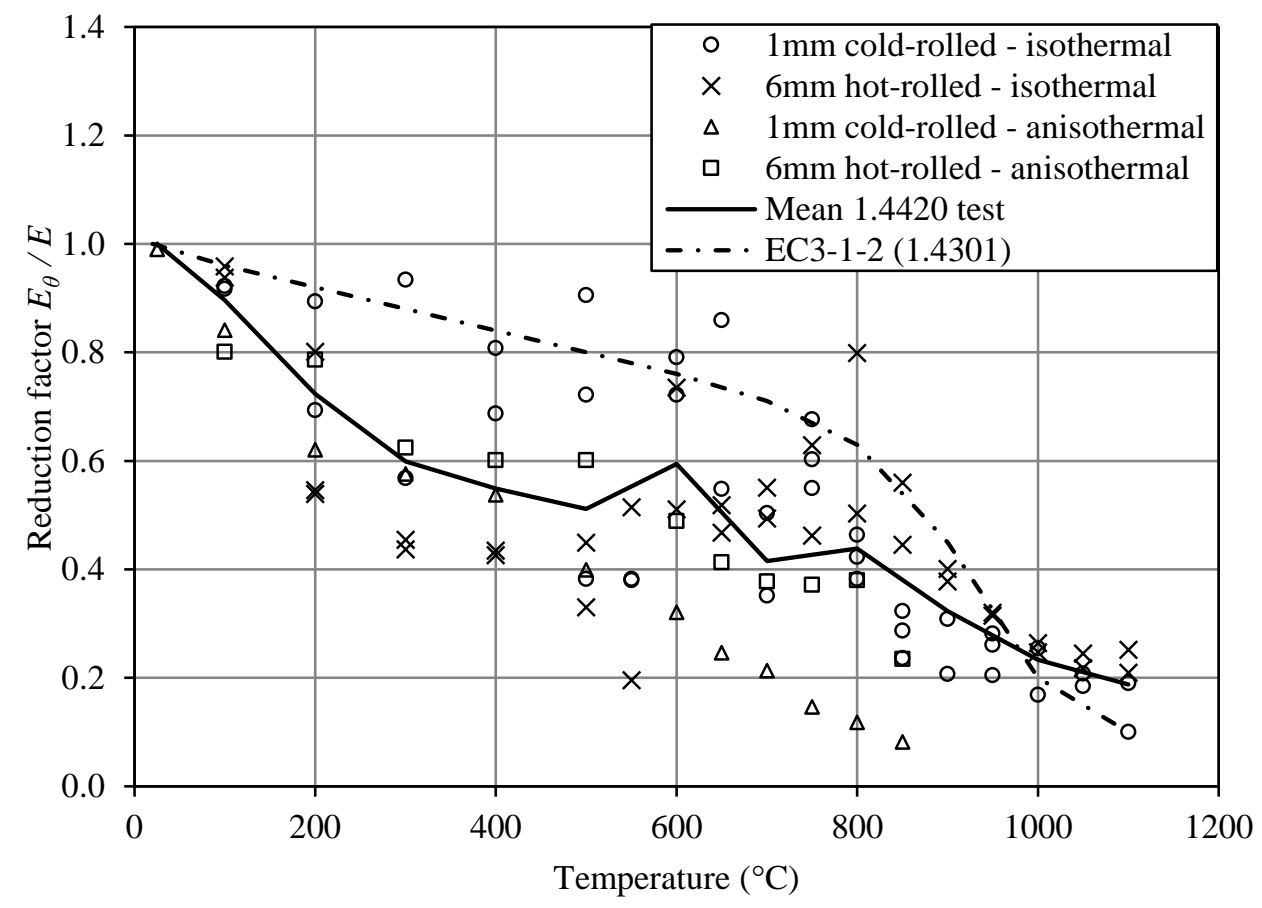

Fig. 8. Reduction factors for modulus of elasticity $\left(E_{\theta} / E\right)$ at elevated temperatures, compared with design values. 


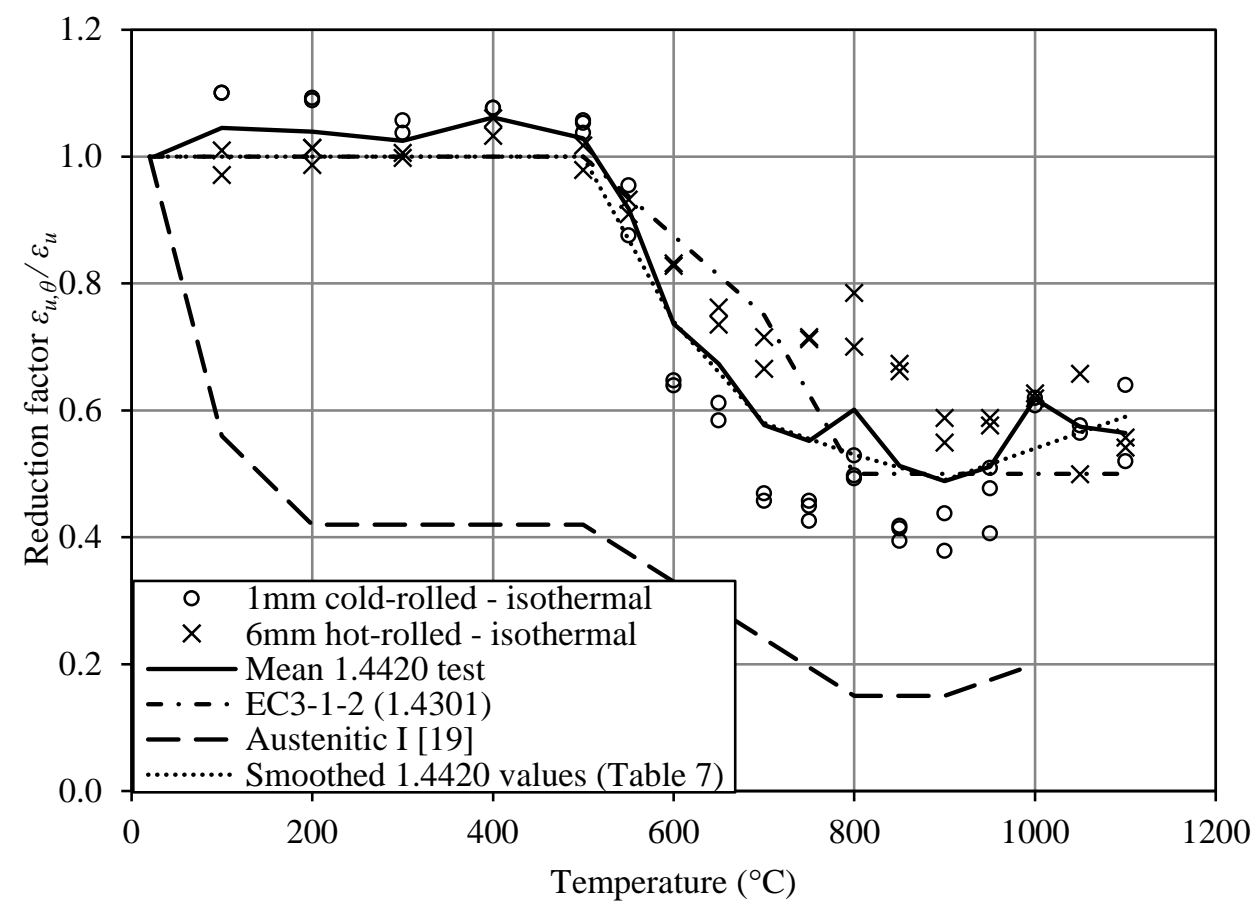

Fig. 9. Reduction factors for ultimate strain $\left(\varepsilon_{u, \theta} / \varepsilon_{u}\right)$ at elevated temperatures, compared with design values.

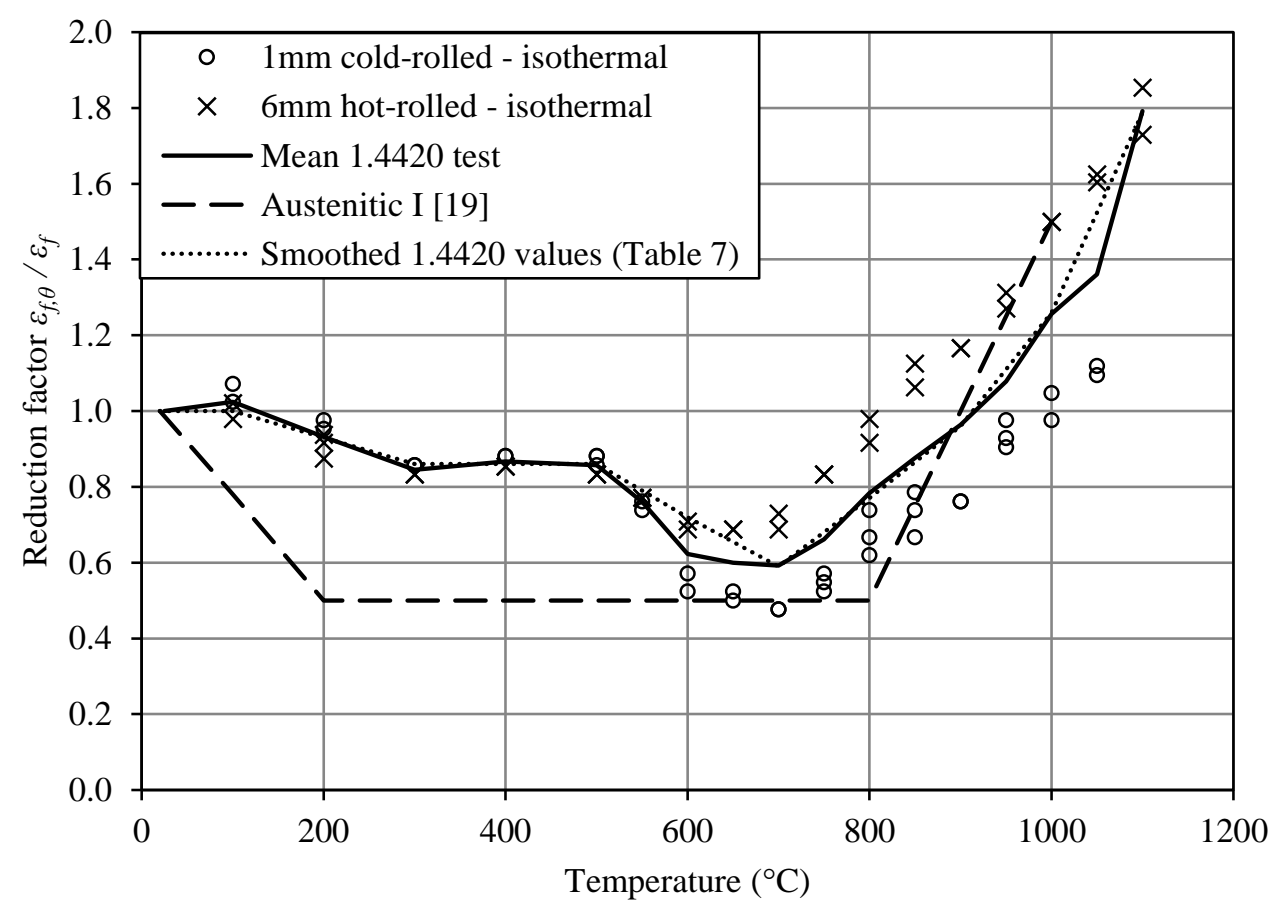

Fig. 10. Reduction factors for fracture strain $\left(\varepsilon_{f, \theta} / \varepsilon_{f}\right)$ at elevated temperatures, compared with design values. 


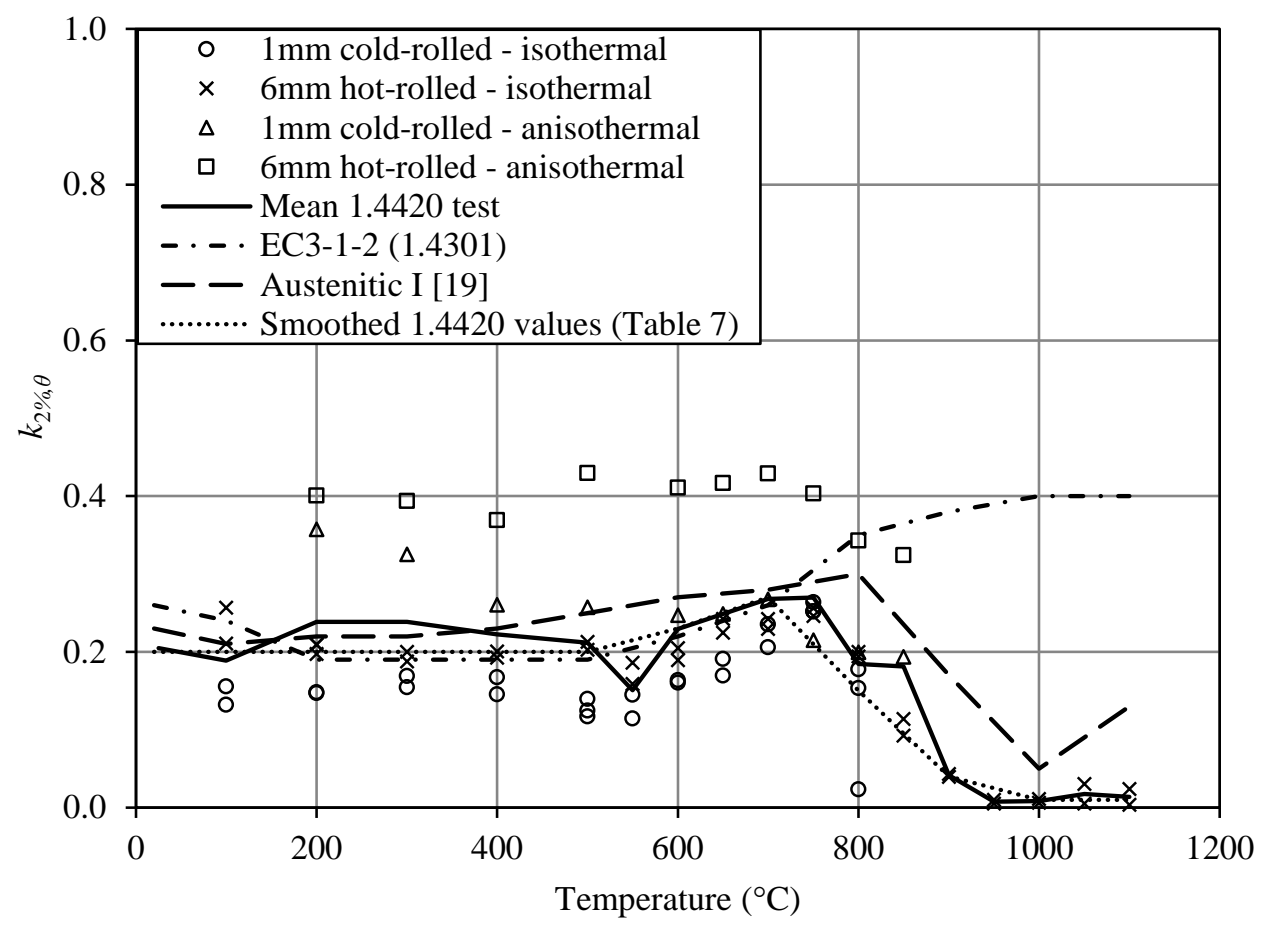

Fig. 11. $k_{2} \%, \theta$ factors at elevated temperatures, compared with design values. 


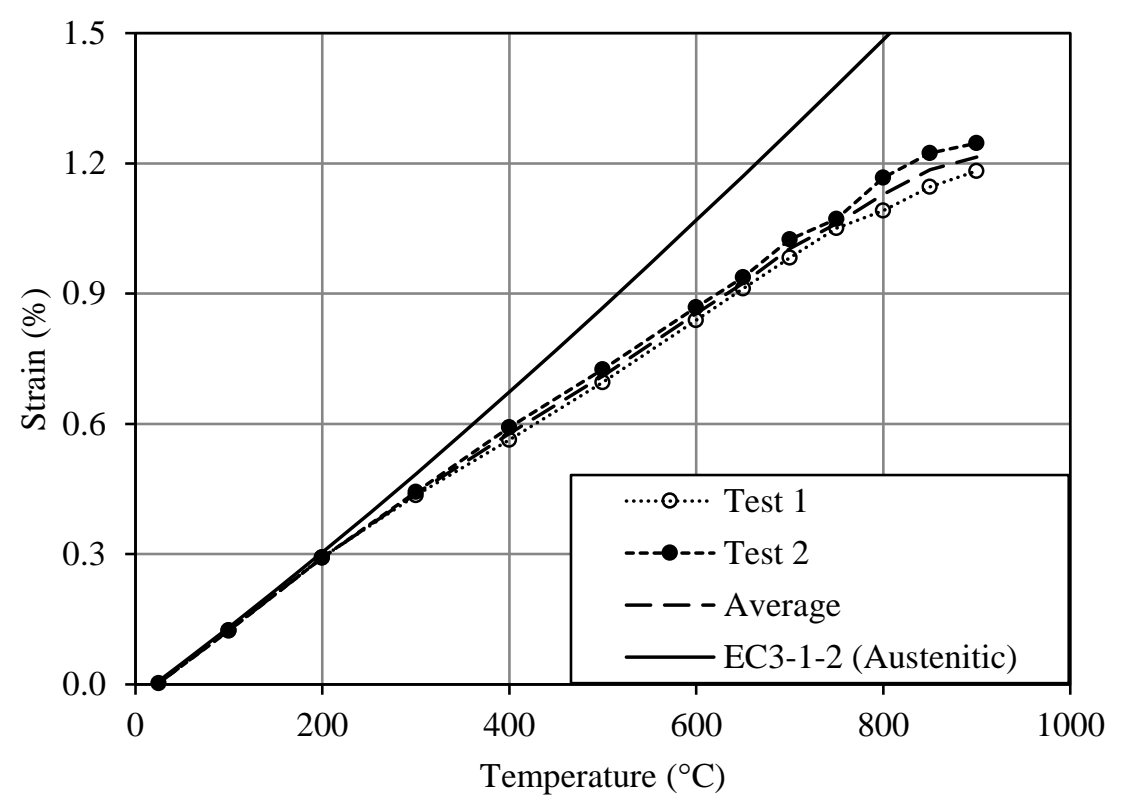

(a) $1 \mathrm{~mm}$ thick cold-rolled material

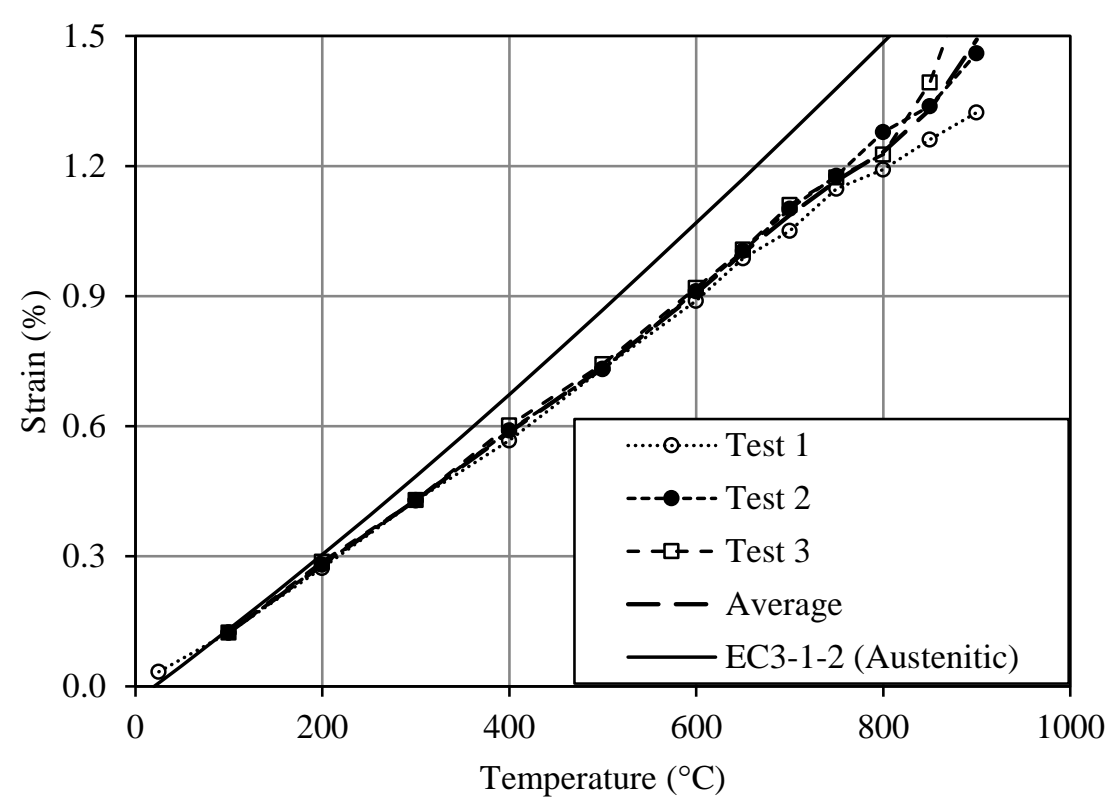

(b) $6 \mathrm{~mm}$ thick cold-rolled material

Fig. 12. Test results of thermal elongation compared with the EC3 thermal expansion curve. 


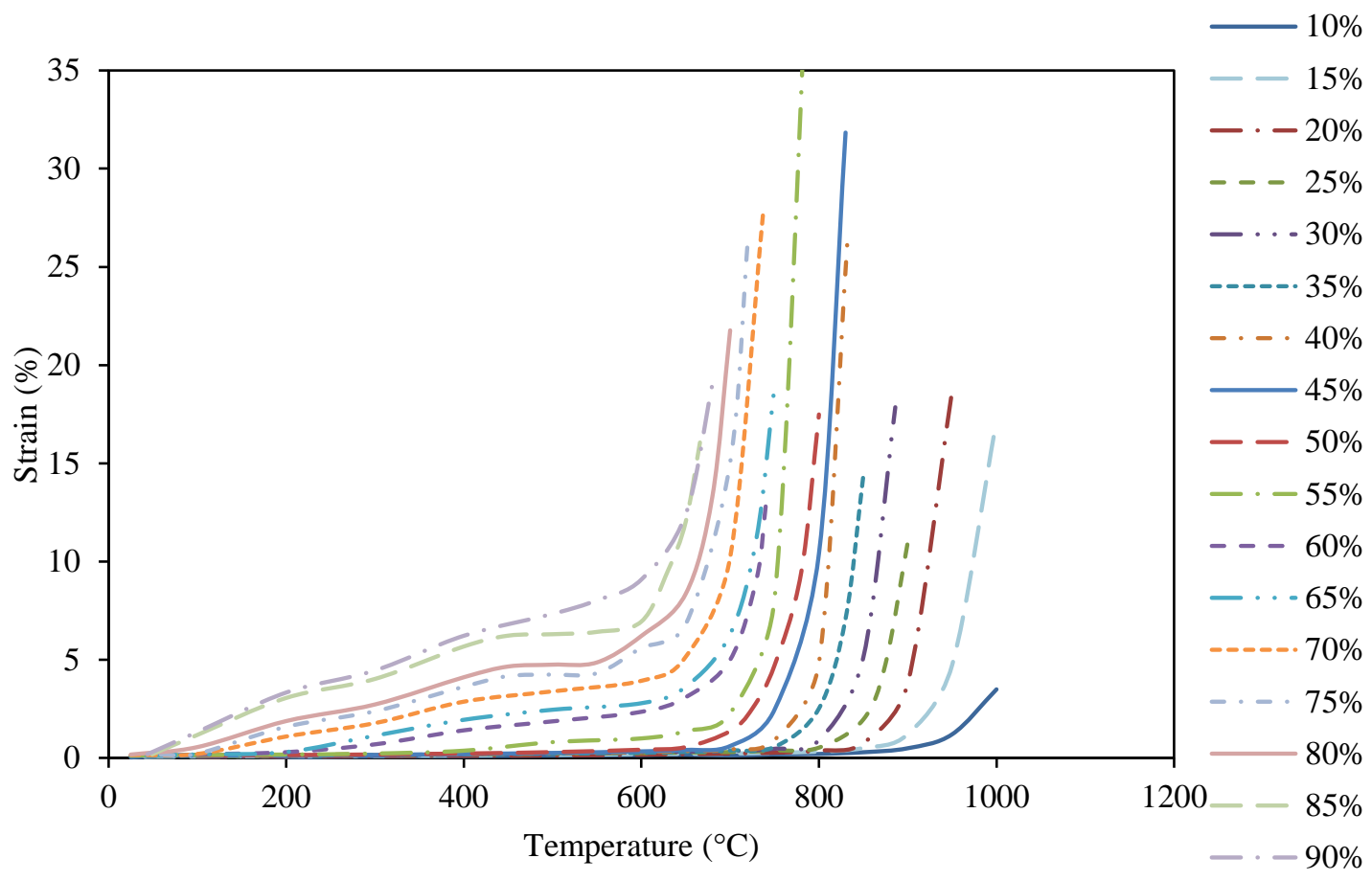

(a) $1 \mathrm{~mm}$ thick cold-rolled material

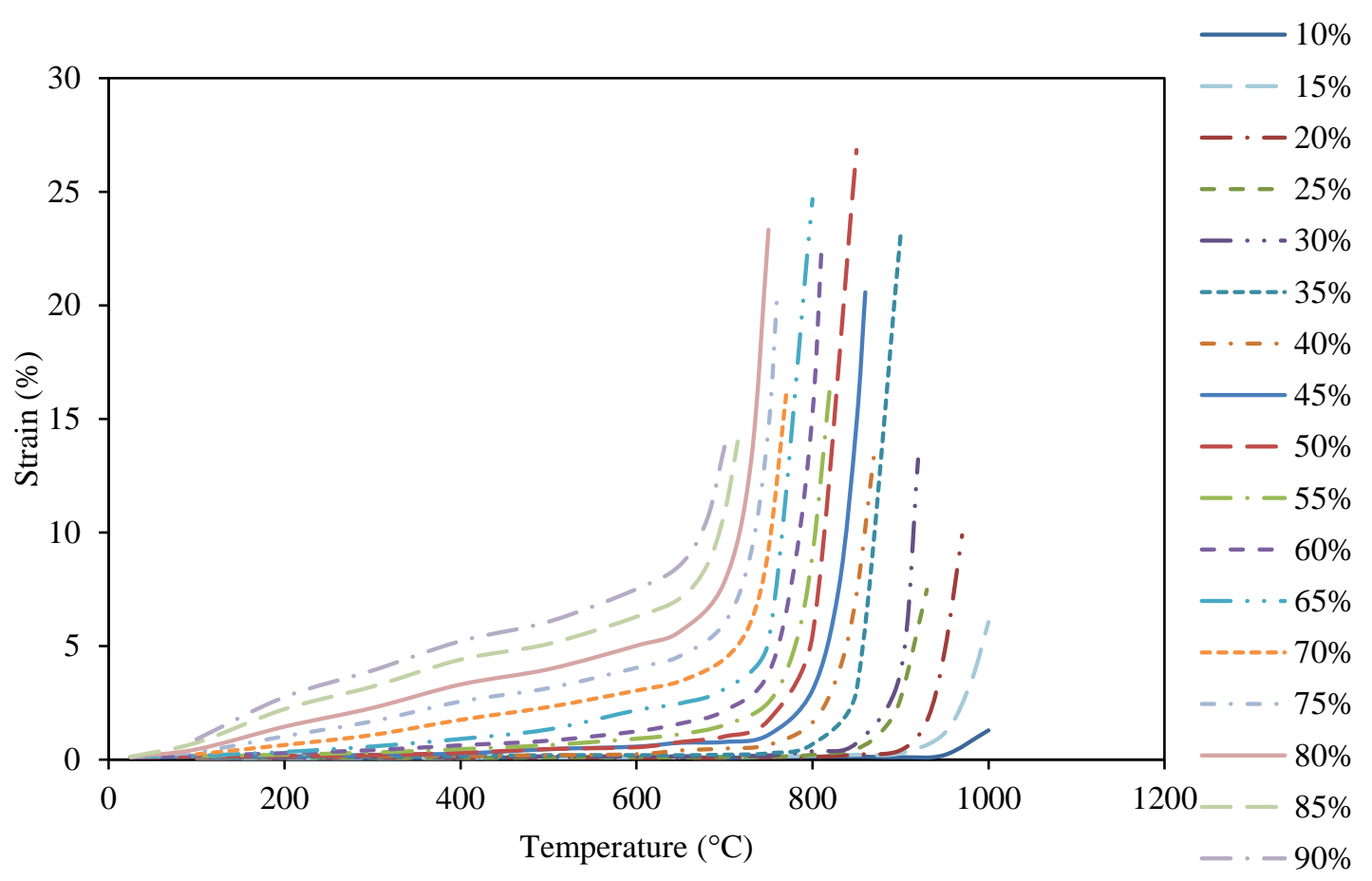

(b) $6 \mathrm{~mm}$ thick hot-rolled material

Fig. 13. Strain-temperature curves obtained from transient state tests. 


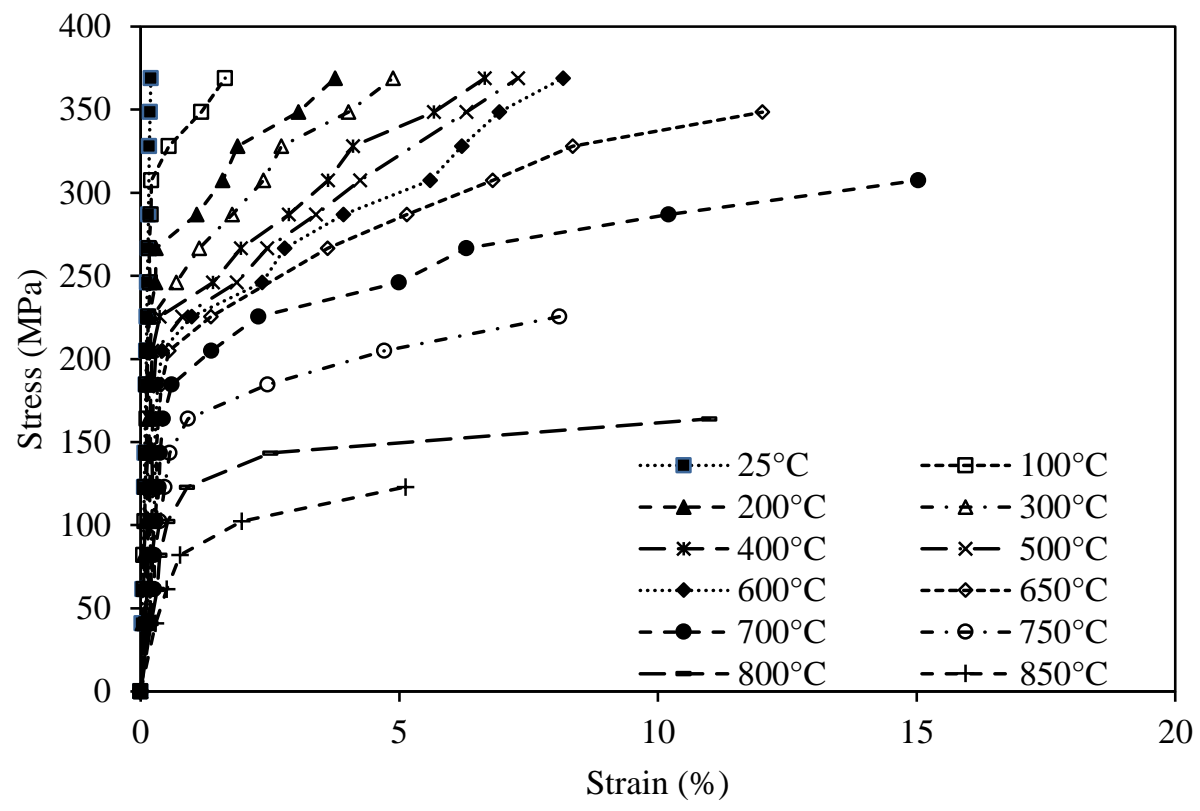

(a) $1 \mathrm{~mm}$ thick cold-rolled material

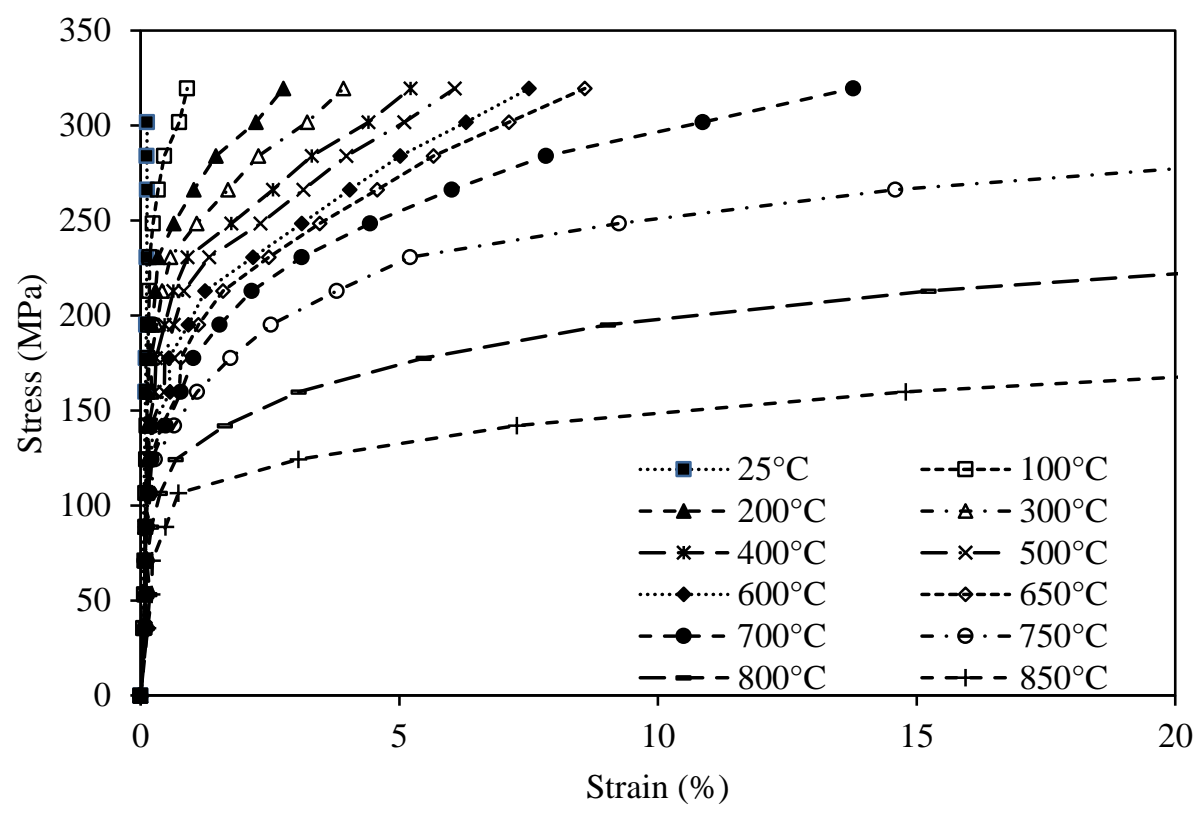

(b) $6 \mathrm{~mm}$ thick hot-rolled material

Fig. 14. Stress-strain curves derived from transient state tests. 


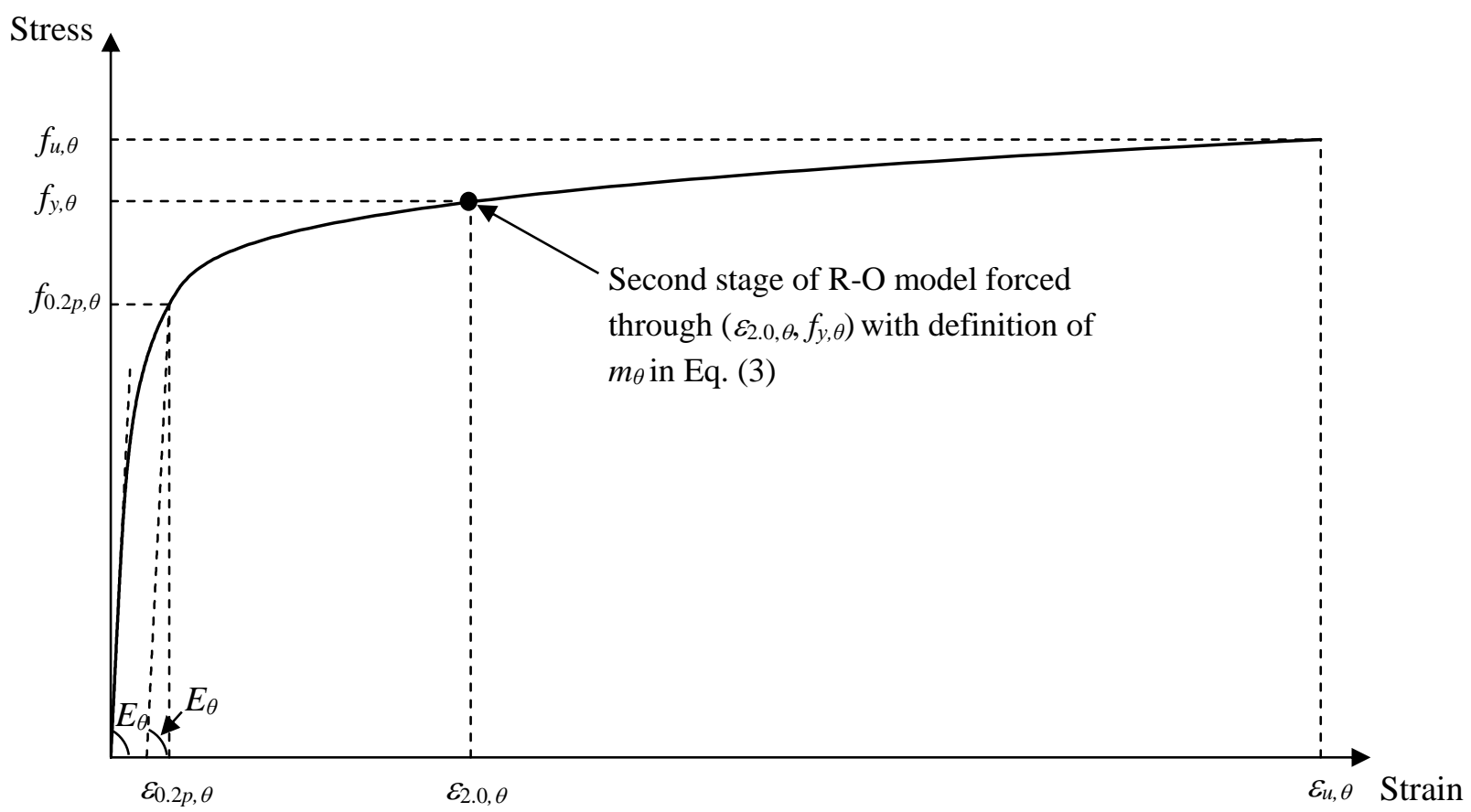

Fig. 15. Elevated temperature two-stage Ramberg-Osgood material model, illustrating that the curve can be forced through the strength at $2 \%$ total strain $\left(f_{y, \theta}\right)$ by defining $m_{\theta}$ using Eq. (3).

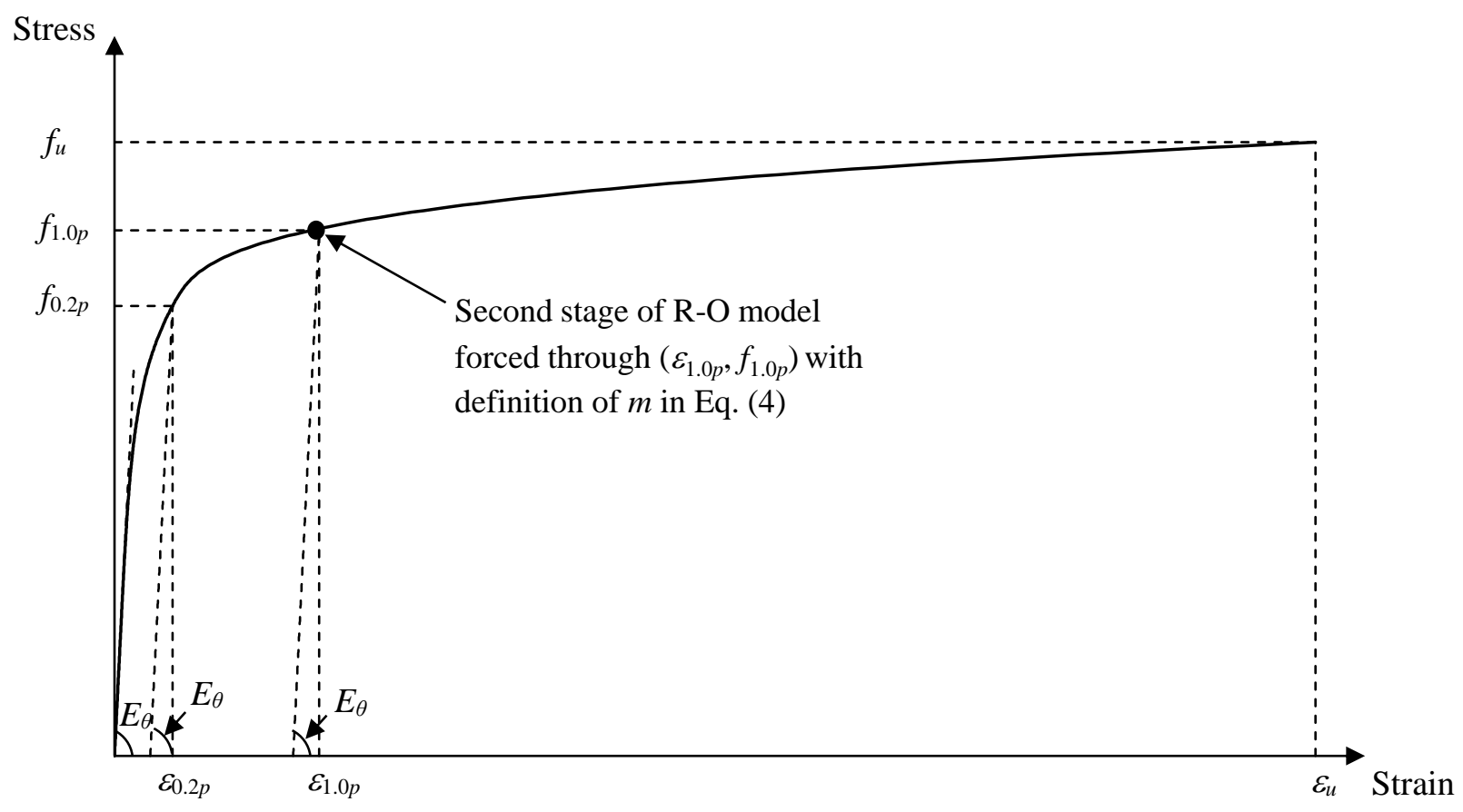

Fig. 16. Room temperature two-stage Ramberg-Osgood material model, illustrating that the curve can be forced through the $1.0 \%$ proof strength $f_{1.0, p}$ by defining $m$ using Eq. (4). 


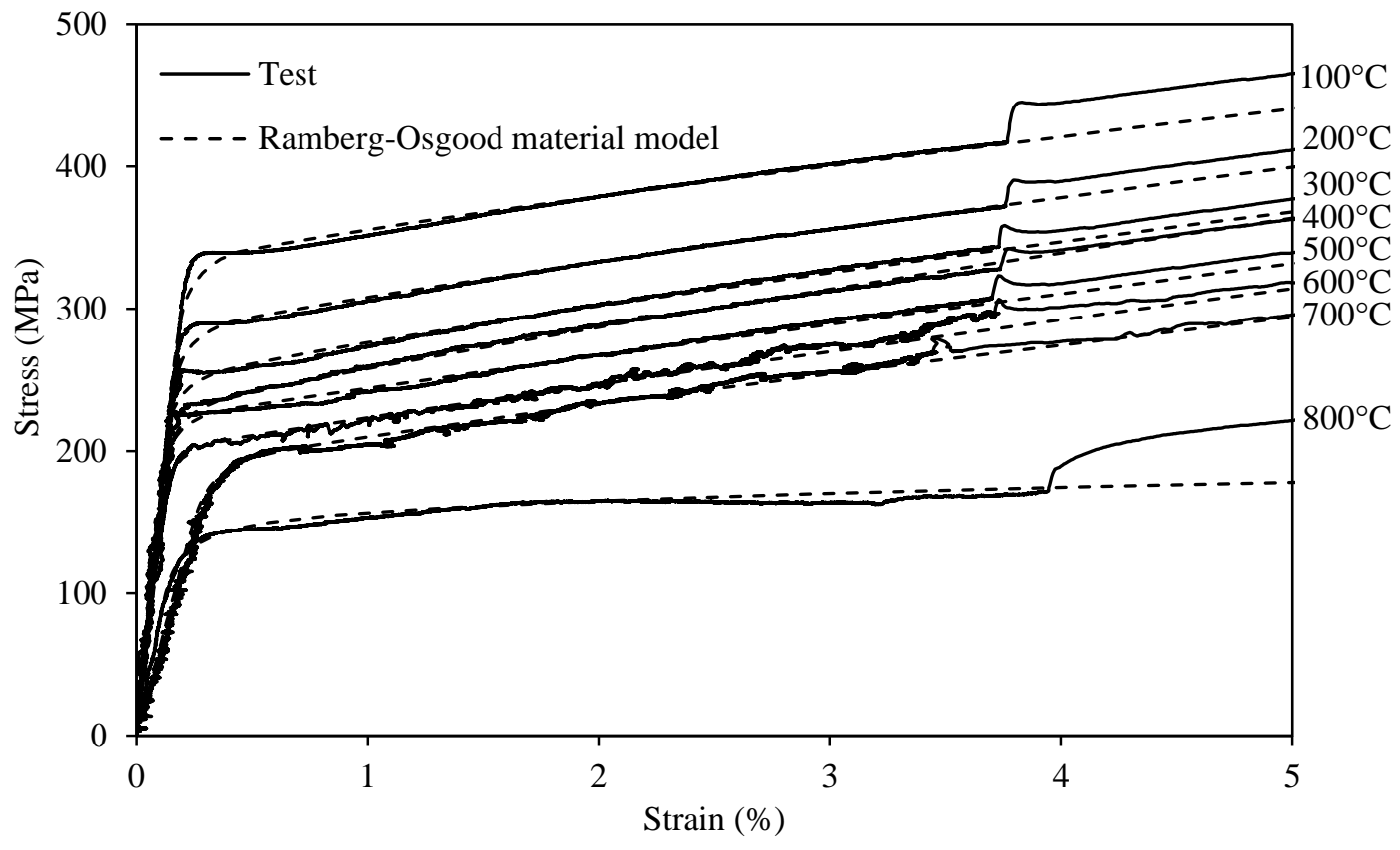

(a) Cold-rolled specimens

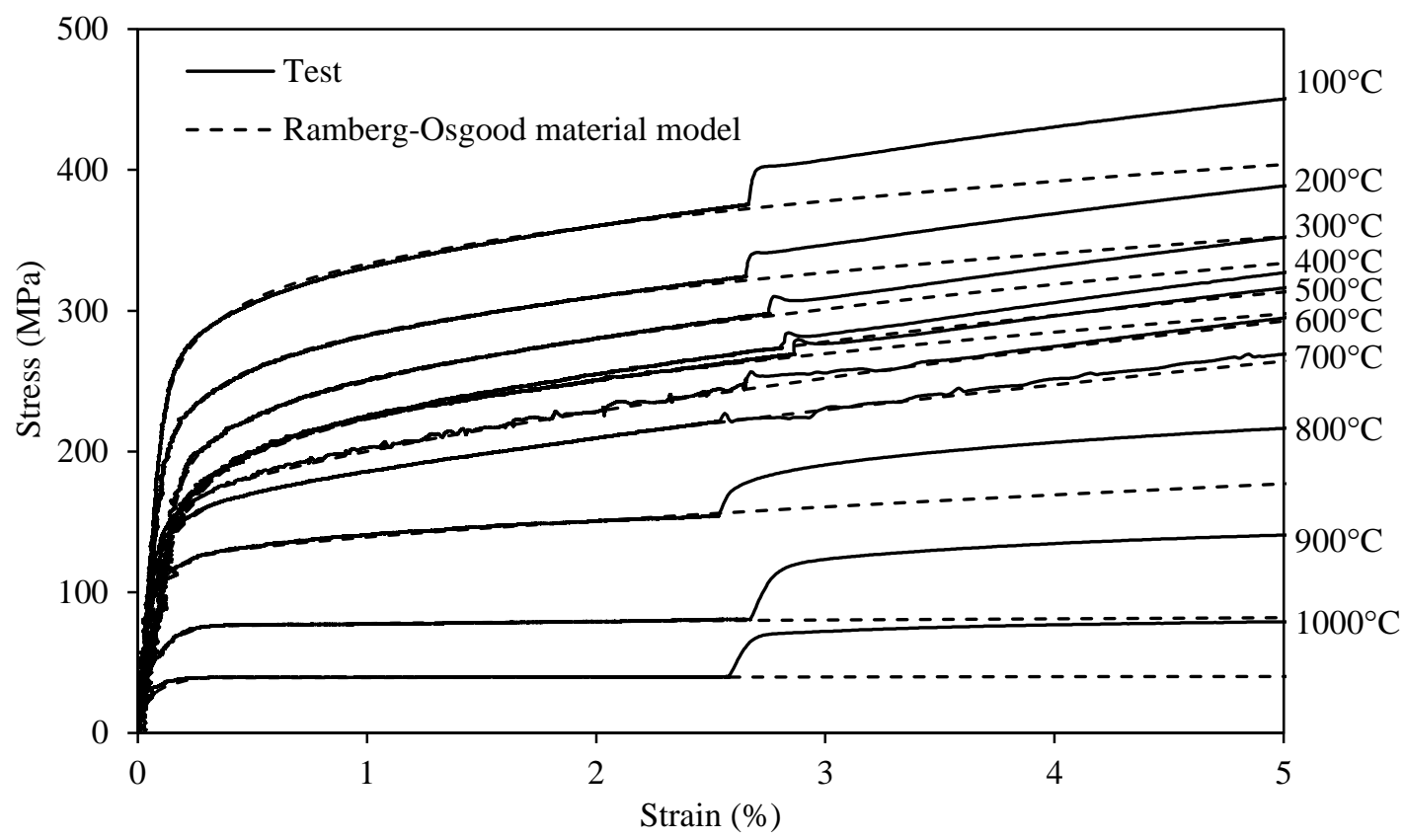

(b) Hot-rolled specimens

Fig. 17. Comparison between typical measured elevated temperature stress-strain curves and twostage Ramberg-Osgood model up to 5\% strain. 